\title{
Maintenance of Mouse Gustatory Terminal Field Organization Is Dependent on BDNF at Adulthood
}

\author{
Chengsan Sun, ${ }^{1}$ Robin Krimm, ${ }^{2}$ and $\oplus^{-D a v i d ~ L . ~ H i l l ~}{ }^{1}$ \\ ${ }^{1}$ Department of Psychology, University of Virginia, Charlottesville, Virginia 22904-4400 and ${ }^{2}$ Department of Anatomical Sciences and Neurobiology, \\ University of Louisville School of Medicine, Louisville, Kentucky 40292
}

The rodent peripheral gustatory system is especially plastic during early postnatal development and maintains significant anatomical plasticity into adulthood. Thus, taste information carried from the tongue to the brain is built and maintained on a background of anatomical circuits that have the capacity to change throughout the animal's lifespan. Recently, the neurotrophin brain-derived neurotrophic factor (BDNF) was shown to be required in the tongue to maintain normal levels of innervation in taste buds at adulthood, indicating that BDNF is a key molecule in the maintenance of nerve/target matching in taste buds. Here, we tested whether maintenance of the central process of these gustatory nerves at adulthood also relies on BDNF by using male and female transgenic mice with inducible CreERT2 under the control of the keratin 14 promoter or under control of the ubiquitin promoter to remove $B d n f$ from the tongue or from all tissues, respectively. We found that the terminal fields of gustatory nerves in the nucleus of the solitary tract were expanded when $B d n f$ was removed from the tongue at adulthood and with even larger and more widespread changes in mice where $B d n f$ was removed from all tissues. Removal of $B d n f$ did not affect numbers of ganglion cells that made up the nerves and did not affect peripheral, whole-nerve taste responses. We conclude that normal expression of $B d n f$ in gustatory structures is required to maintain normal levels of innervation at adulthood and that the central effects of $B d n f$ removal are opposite of those in the tongue.

Key words: cytokeratin 14; neurotrophin; plasticity; taste; terminal field; ubiquitin

Significance Statement

BDNF plays a major role in the development and maintenance of proper innervation of taste buds. However, the importance of BDNF in maintaining innervation patterns of gustatory nerves into central targets has not been assessed. Here, we tested whether $B d n f$ removal from the tongue or from all structures in adult mice impacts the maintenance of how taste nerves project to the first central relay. Deletion of $B d n f$ from the tongue and from all tissues led to a progressively greater expansion of terminal fields. This demonstrates, for the first time, that BDNF is necessary for the normal maintenance of central gustatory circuits at adulthood and further highlights a level of plasticity not seen in other sensory system subcortical circuits.

\section{Introduction}

Impressive morphological, physiological, and behavioral changes characterize the postnatal development of the rodent gustatory system. This is especially evident for the age-related changes in neural circuits that transmit taste information from taste buds directly to the brain. The terminal field size of the nerves carrying taste information from taste buds directly to the nucleus of the

\footnotetext{
Received March 27, 2018; revised May 26, 2018; accepted June 17, 2018.

Author contributions:C.S., R.K., and D.L.H. designed research;C.S., R.K., and D.L.H. performed research;C.S., R.K., and D.L.H. analyzed data; D.L.H. wrote the paper.

This work was supported by National Institutes of Health Grants DC000407 and DC006938 (to D.L.H.) and DC007176 (to R.F.K.). We thank Rolf Skyberg for comments on this manuscript.

The authors declare no competing financial interests.

Correspondence should be addressed to Dr. David L. Hill, Department of Psychology, P.0. Box 400400, University of Virginia, Charlottesville, VA 22904. E-mail: dh2t@virginia.edu.

DOI:10.1523/JNEUROSCI.0802-18.2018

Copyright $\odot 2018$ the authors $\quad 0270-6474 / 18 / 386873-15 \$ 15.00 / 0$
}

solitary tract (NST) in the medulla decreases by as much as four times within a 20 postnatal day period (Mangold and Hill, 2008; Zheng et al., 2014). This normal process can be interrupted by early embryonic and lifelong maternal dietary manipulations (May and Hill, 2006; Mangold and Hill, 2008) and by deleting the transduction channel for sodium salt taste throughout development (Sun et al., 2017). Surprisingly, these circuits remain plastic into adulthood. Sectioning two of three gustatory nerves at adulthood induces expansion of the intact nerve's terminal field by five times within $15 \mathrm{~d}$ of the denervation (Corson and Hill, 2011). Moreover, inducibly deleting the sodium taste transduction channel at adulthood leads to an expanded organization similar to that found in immature animals (Skyberg et al., 2017). This inherent and lifelong ability for taste neurons to remodel may be attributable, in part, to the continual turnover of taste bud cells throughout development. That is, the peripheral limb of these nerves must accommodate the 
change in receptive fields that occur approximately every $10 \mathrm{~d}$ (Beidler and Smallman, 1965).

Studies of nerve/target matching during development and maintenance of innervation in taste buds at adulthood point to the neurotrophin brain-derived neurotrophic factor (BDNF) as a likely candidate molecule regulating proper innervation by taste axons. BDNF regulates the initial innervation of taste buds by directing gustatory nerve fibers to their targets (Mbiene and Mistretta, 1997; Ma et al., 2009). It is then downregulated with age and expressed in a subpopulation of taste bud cells (Yee et al., 2003; Huang and Krimm, 2010). Although emerging evidence supports BDNF as being critical during development of peripheral gustatory circuits, the extent it is required for maintenance of these circuits at adulthood is unclear. Recently, Meng et al. (2015) did the first study to examine the effects of BDNF removal at adulthood on the maintenance of innervation patterns in the gustatory system. They genetically removed BDNF from taste bud cells in adult mice and showed a $40 \%$ loss of taste bud innervation and some taste bud cells. Maintenance of the peripheral innervation pattern was not retained.

If BDNF is required to maintain the innervation of taste buds at adulthood, we asked here whether it is also required to maintain the central limb of these same nerves. We used the same genetic strategy as Meng et al. (2015) to inducibly delete Bdnf from taste bud cells or from all tissues and found that the terminal field sizes dramatically increased in the brainstem. Thus, the same experimental manipulation led to opposite effects on the central process of gustatory nerves compared with that on the peripheral process.

\section{Materials and Methods}

\section{Animals}

All experiments were approved by the University of Virginia Animal Care and Use Committee and followed guidelines set forth by the National Institutes of Health and the Society for Neuroscience. Experimental animals were transgenic mice in which the gene for $B d n f$ was inducibly removed from the tongue or from all cells at adulthood. These animals were made, respectively, by crossing mice that expressed CreERT2 under control of the keratin 14 promoter (https://www.jax.org/strain/005107; RRID:IMSR_JAX:005107) or under control of the ubiquitin promoter (https://www.jax.org/strain/007001; RRID:IMSR_JAX:007001) with mice in which exon 5 of the $B d n f$ gene was floxed (https://www.jax.org/ strain/004339; RRID:IMSR_JAX:004339). We, and others (Meng et al., 2015), found that $60-80 \%$ of $B d n f$ expression in the tongue remained in both groups of mice after a single injection of $6 \mathrm{mg}$ of tamoxifen, as measured by real-time transcription-PCR (qPCR). To decrease the amount of $B d n f$ expression to much lower levels, we bred mice so that one of the alleles was null for $B d n f$ (https://www.jax.org/strain/002266; RRID:IMSR_JAX:002266) and the other allele was floxed. We also increased the administration of tamoxifen (T5648, Sigma; mixed in corn oil, $188 \mathrm{ng} / \mathrm{g}$ body weight) to once each weekday for 3 weeks. Tamoxifen was delivered by oral gavage (Ruzankina et al., 2007), beginning at $40 \mathrm{~d}$ of age. No treatment was administered during the weekends. Therefore, our experimental animals had the genotype of K14-CreER $B d n f^{l o x /}$ TAM or UBC-CreER $B d n f^{l o x} /$ - TAM for mice in which $B d n f$ expression was deleted from the tongue or from all cells, respectively. For clarity, we will refer to these two inducible knock-out mice as K14-Bdnf iKO and UBC$B d n f$ iKO mice, respectively.

Two control groups were used for comparisons with the two experimental groups. One group consisted of mice that were littermates to experimental animals but did not have any of the transgenes (control; $B d n f^{+/+}$). Another group had all of the transgenes for K14-CreER $B d n f^{\text {lox } / \text { - }}$ mice or for UBC-CreER $B d n f^{\text {lox } /-}$ mice but did not receive administration of tamoxifen (K14-Bdnf iKO No TAM and UBC-Bdnf iKO No TAM, respectively). Thus, these latter two groups were used to control for the effects of the heterozygous removal of the Bdnf gene throughout development.

\section{Tissue collection}

To establish that mice used here had reduced $B d n f$ expression in the anterior tongue, in the geniculate ganglion, and in the NST, we used qPCR procedures similar to that described by Huang and Krimm (2010) and Sun et al. (2015). Briefly, the anterior two-thirds of fresh tongues from mice (controls, $n=3$ : two males, one female; K14-Bdnf iKO No TAM, $n=6$ : three males, three females; K14-Bdnf iKO, $n=7$ : three males, four females; UBC-Bdnf iKO No TAM, $n=6$ : three males, three females; UBC-Bdnf iKO, $n=6$ : four males, two females) were collected and cut at the midline, rinsed with cold PBS, and incubated in sterile dispase I solution (BD Biosciences) for $60 \mathrm{~min}$ at $37^{\circ} \mathrm{C}$. Epithelial sheets of the tongue were then peeled from the underlying mesenchyme, transferred into separate tubes containing RNAlater (Thermo Fisher Scientific), and stored at $-80^{\circ} \mathrm{C}$ until RNA extraction. Epithelial sheets of the tongue were then peeled from the underlying connective tissue for RNA extraction. Similarly, fresh geniculate ganglia (controls, $n=3$ : two males, one female; K14-Bdnf iKO No TAM, $n=3$ : one male, two females; K14-Bdnf iKO, $n=7$ : three males, four females; UBC-Bdnf iKO No TAM, $n=3$ : two males, one female; UBC- $B d n f \mathrm{iKO}, n=3$ : two males, one females) and the rostral portion of the NST (controls, $n=5$ : two males, three females; K14-Bdnf iKO No TAM, $n=5$ : two males, three females; K14-Bdnf $\mathrm{iKO}, n=5$ : two males, three females; UBC-Bdnf $\mathrm{iKO}$ No TAM, $n=5$ : three males, two females; UBC-Bdnf iKO, $n=3$ : two males, one female) were dissected, transferred into separate tubes containing RNAlater (Ambion), and stored at $-80^{\circ} \mathrm{C}$ until RNA extraction. Fresh geniculate ganglia were collected after removal of the brain and visualized within the ventral cranium. The rostral NST was removed after horizontally sectioning the brainstem with a vibratome at $200 \mu \mathrm{m}$ in cold PBS. The region of interest (anterior half of the NST) was removed with a sterile scalpel under a dissecting microscope. The NST is visible in unstained tissue and can be easily seen as a clear structure compared with surrounding tissue. Brainstem landmarks (e.g., fourth ventricle, solitary tract, hypoglossal nucleus) were used to identify dorsal to ventral extents of the NST.

\section{RNA extraction and measurement}

Total RNA from anterior tongue epithelia, geniculate ganglia, and NST was extracted as described previously (Huang and Krimm, 2010; Sun et al., 2015). RNA integrity numbers (RINs) were used to estimate the RNA quality. Only RNA samples with RINs $>8.0$ were used. The same amount of RNA from control and tamoxifen-treated mice was used. RNA was also treated in parallel in the absence of reverse transcriptase to examine for genomic DNA contamination. qPCR was performed by the 7500 Fast Real-Time PCR System (Applied Biosystems) using the TaqMan Universal PCR kit (Applied Biosystems) and oligonucleotide primer/probe sets (Huang and Krimm, 2010; Sun et al., 2015). TaqMan probes were labeled at the $5^{\prime}$ end with a fluorescent reporter dye (FAM) and at the $3^{\prime}$ end with a quencher dye (TAMRA).

The sequences of primers and probes are as follows: BDNF (forward primer, TGCAGGGGCATAGACAAAAGG; reverse primer, CTTATGAATCGCCAGCCAATTCTC; probe, ACTGGAACTCGCAATGCCGAACTACCCA) and glyceraldehyde 3-phosphate dehydrogenase (GAPDH; forward primer, CTGGGACGACATGGAGAAGATC; reverse primer, CAACCTGGTCCTCAGTGTAGC; probe, CGTGCCGCCTGGAGAAACCTGCC).

qPCRs were performed in a $20 \mu$ l total volume with $1 \times$ Master Mix, 720/200 nM primer/probe sets. PCR efficiencies were determined by performing PCR with serial (10-fold) dilutions of cDNA in parallel. All samples were run in parallel with the housekeeping gene mouse GAPDH, to normalize cDNA loading. Each assay was performed in triplicate. PCR was performed for 40 cycles at $95^{\circ} \mathrm{C}$ for $15 \mathrm{~s}$ and at $60^{\circ} \mathrm{C}$ for $1 \mathrm{~min}$.

\section{qPCR analyses}

For qPCR, the comparative $2^{-\Delta \Delta C T}$ method was used to determine the relative $B d n f$ gene expression levels (Huang and Krimm, 2010; Sun et al., 2015). The normalized expression of the $B d n f$ was calculated as normalized expression $=\left(E_{\mathrm{BDNF}}\right)^{\Delta \mathrm{CT}}$ target(control - sample $) /\left(E_{\mathrm{ref}}\right){ }_{\mathrm{GAPDH}(\text { control }- \text { sample })}^{\Delta \mathrm{CT}}$. 
$E_{\mathrm{Bdnf}}$ and $E_{\mathrm{GAPDH}}$ represent the reaction efficiency of the respective gene, and $\Delta \mathrm{CT}$ is the cycle difference between the control and the sample.

\section{BDNF immunohistochemistry}

To examine whether the group-related effects of $B d n f$ expression are reflected in the presence of BDNF in the NST, we performed immunohistochemical experiments that focused on the NST in UBC-Bdnf iKO mice. Two control mice (one male and one female) and two UBC-Bdnf $\mathrm{iKO}$ mice (one male and one female) were perfused as described in the nerve-labeling section. Sections were then incubated in BDNF antibody raised in rabbit at a concentration of 1:200 (ANT-010, Alomone Labs; RRID:AB_2039756) in 1\% BSA and 0.3\% Triton X-100 in $0.1 \mathrm{M}$ PBS overnight. After rinsing with PBS (six times for $10 \mathrm{~min}$ ), sections were incubated in a donkey anti-rabbit secondary antibody conjugated with 1:400 Alexa Fluor 488 (711-545-152, Jackson ImmunoResearch Laboratories; RRID:AB_2313584) for $1.5 \mathrm{~h}$. Then sections were rinsed and mounted on slides and examined on a fluorescent microscope at $10 \times$ and $20 \times$.

\section{Fluorescent anterograde nerve labeling}

Procedures used to fluorescently label the chorda tympani (CT), which innervates taste buds on the anterior two-thirds of the tongue; the greater superficial petrosal nerve (GSP), which innervates taste buds on the palate; and the glossopharyngeal nerve (IX), which innervates taste buds on the posterior tongue, were the same as that described previously in mouse (Sun et al., 2015, 2017). Briefly, the CT, GSP, and IX nerves were labeled in six (three males, three females) controls, three (one male, two females) K14-Bdnf iKO No TAM, seven (three males, four females) K14$B d n f \mathrm{iKO}$, four (two males, two females) UBC-Bdnf iKO No TAM, and five (three males, two females) UBC- $B d n f$ iKO mice with anterograde tracers to determine the volume and densities of label among gustatory afferent terminal fields in the NST. All animals were between 4 and 5 months old at the time of nerve labeling. Therefore, for experimental groups, the nerve labeling occurred $\sim 60 \mathrm{~d}$ after the last administration of tamoxifen. The anterograde labeling surgery for mice in the two control groups were aged matched with the experimental groups. Mice were sedated with a $0.32 \mathrm{mg} / \mathrm{kg}$ injection of Domitor (medetomidine hydrochloride, Pfizer Animal Health; intramuscularly) and anesthetized with $40 \mathrm{mg} / \mathrm{kg}$ Ketaset (ketamine hydrochloride, Fort Dodge Animal Health; intramuscularly). A water-circulating heating pad was used to maintain body temperature. Using the same surgical approach detailed by Sun et al. $(2015,2017)$, the CT and GSP nerves were cut near and peripheral to the geniculate ganglion in the tympanic bulla, crystals of $3 \mathrm{kDa}$ tetramethylrhodamine dextran amine were then applied to the proximal cut end of the GSP, and $3 \mathrm{kDa}$ biotinylated dextran amine was applied to the proximal cut end of the CT. A small amount of Kwik-Sil (World Precision Instruments) was then placed over the cut end of the nerves to prevent crystals from diffusing from the site of the intended label. The IX was isolated medial to the tympanic bulla and was cut peripheral to the petrosal ganglion and placed on a small piece of Parafilm. Crystals of 3 $\mathrm{kDa}$ cascade blue dextran amine were applied to the proximal cut end of the IX nerve. All dextran amine conjugates were purchased from Invitrogen. Vaseline and a layer of Parafilm were placed on top of the IX to keep the dextran in place. Animals were then given intramuscular injections of $5 \mathrm{mg} / \mathrm{ml}$ Antisedan (atipamezole hydrochloride, Pfizer Animal Health) to promote reversal of anesthesia. After a $48 \mathrm{~h}$ survival, animals were deeply anesthetized with urethane and transcardially perfused with Krebs-Henseleit buffer, pH 7.3, followed by $4 \%$ paraformaldehyde, $\mathrm{pH} 7.2$.

\section{Tissue preparation}

Brains were removed and postfixed, and the medulla was blocked and sectioned horizontally on a vibratome at $50 \mu \mathrm{m}$ (Sun et al., 2015, 2017). We sectioned tissue in the horizontal plane because it allows visualization of the entire rostrocaudal and mediolateral extent of the terminal fields in the NST with the smallest number of sections ( $~ 10$ sections per mouse) and is also the plane in which the axons branch from the solitary tract and project primarily medially in rodents (Davis, 1988; Whitehead, 1988; Lasiter et al., 1989). Highly detailed descriptions of the mouse NST and the projection of the CT to this nucleus and subnuclei have been de- scribed in coronal sections (Bartel and Finger, 2013; Ganchrow et al., 2014). Therefore, we also sectioned brainstems in the coronal section to qualitatively examine group-related differences in the innervation of NST subnuclei.

Sections were incubated for $1 \mathrm{~h}$ in PBS containing 0.2\% Triton X-100 with 1:500 streptavidin Alexa Fluor 647 (016-600-084, Jackson ImmunoResearch Laboratories; RRID:AB_2341101) and 1:500 rabbit antiCascade Blue (A-5760, Thermo Fisher Scientific; RRID:AB_2536192) at room temperature. Streptavidin Alexa Fluor 647 was used to visualize the biotinylated dextran amine-labeled CT-positive terminals. Rabbit antiCascade Blue was used as a primary antibody to detect Cascade Bluelabeled IX terminal fields and was followed with a $1 \mathrm{~h}$ reaction with 1:500 goat anti-rabbit Alexa Fluor 488 (A-21206, Thermo Fisher Scientific; RRID:AB_2535792). This secondary antibody was used to visualize IX nerve terminals. Visualization of tetramethylrhodamine, which labeled GSP terminal fields, did not require further processing.

\section{Confocal microscopy and analyses of terminal fields}

Imaging. Terminal fields were imaged using a Nikon 80i microscope fitted with a Nikon C2 scanning system (Nikon Instruments) and a $10 \times$ objective (NA, 0.45; CFIPlanApo, Nikon). The nerve labels were matched for the wavelengths of the three lasers in the system (argon laser, $488 \mathrm{~nm}, 10 \mathrm{~mW}$, IX; DPSS laser, $561 \mathrm{~nm}, 10 \mathrm{~mW}$, GSP; modulated diode laser, $638 \mathrm{~nm}, 20 \mathrm{~mW}$, CT). Sequential optical sections were captured every $3 \mu \mathrm{m}$ for each $50 \mu \mathrm{m}$ section. Images were obtained with settings adjusted so that pixel intensities were near (but not at) saturation. A transmitted light image at $4 \times($ Nikon PlanFluor; NA, 0.13$)$ and at $10 \times$ was captured for every physical section containing the labeled terminal field. This permitted an accurate registration of dorsal to ventral brainstem sections among animals using common brainstem landmarks $(4 \times)$ and identification of NST borders $(10 \times)$. Group assignment for each set of confocal stacks/mouse was blind to the investigator thresholding the images.

Analyses of total terminal field volume. Methods used to analyze terminal field volumes and densities were described previously in detail (Sun et al., 2015, 2017). Briefly, quantification of terminal field volume was achieved through the use of custom ImageJ-based software. Each image stack was initially rotated so that the solitary tract was oriented vertically. The border of the NST was outlined for each physical section through the use of the corresponding transmitted light image, and the stack was then cropped to include only the NST. The IsoData thresholder algorithm (Ridler and Calvard, 1978) was applied to yield a binary image stack of the labeled pixels above threshold, and a particle analysis was then performed to quantify the pixel area above threshold for each channel. Volumes from each physical section were summed to yield the total terminal field volume for each mouse. The resultant volume represents an unbiased experimenter measure of the amount of label. Additionally, the volume of colocalization between the terminal fields of two nerves (CT with GSP, GSP with IX, CT with IX) and among all three nerves (CT, GSP, and IX) was determined in a similar manner as described for each single label.

We chose to include axons (e.g., the solitary tract) along with the terminal fields for all animals in our analyses because of the difficulty in accurately deleting these elements from each optical section. Accordingly, the absolute volumes that we show here include the composite terminal field and axons. Since there is no obvious reorganization of nerve tracts among groups, we make the assumption that including the solitary tract in our measurements had a similar quantitative effect among groups.

Analyses of terminal field volume and density of labels in dorsoventral zones. The analyses of terminal field volumes and density here is the same as was done to study the role of $B d n f$ overexpression in the tongue on terminal field organization in the NST (Sun et al., 2015). The NST was subdivided into $X, Y$, and $Z$ planes to help identify where terminal field organization of each nerve and the overlaps with other terminal fields occurred. For the mediolateral and rostrocaudal analyses $(X$ and $Y)$, the NST in the horizontal plane was subdivided into a grid consisting of uniform boxes of $100 \times 100$ pixels. The NST was aligned relative to the 
grid, with the intersection of the most medial and most rostral borders of the NST as the 0,0 coordinate.

For analyses in the dorsoventral planes $(Z)$, we examined the volume of the labeled terminal field in four dorsoventral zones and followed the method detailed by Sun et al. (2015). Briefly, in horizontal sections, we subdivided the NST into four zones: far dorsal, dorsal, intermediate, and ventral zones [see Sun et al. (2015) for definitions of zones]. The landmarks used to define each zone were consistent among the groups. To check for reliability, a person naive to previous assignment of sections into zones assigned sections for each animal into the four zones. With minor exceptions, the dorsoventral zone assignments among investigators were the same.

Density by dorsoventral zones. Density measures were not statistically analyzed but were qualitatively examined through heat maps for each dorsoventral zone containing a $5 \times 10$ (column $\times$ row) grid.

Examination of terminal fields in coronal sections. The NST from two UBC- $B d n f$ iKO No TAM mice (females, $>90 \mathrm{~d}$ old) and two UBC- $B d n f$ iKO mice (females, $>90 \mathrm{~d}$ old) were sectioned coronally on a vibratome at $50 \mu \mathrm{m}$ and imaged as described above. Coronal sections were used to examine the extent of terminal field expansion and overlapping fields in the NST. No quantitative measurements were taken. Coronal sections were also imaged with transmitted light to allow visualization of NST and brainstem landmarks to qualitatively compare terminal field labels among sections in the same rostrocaudal plane.

Geniculate ganglion and petrosal ganglion cell number. All mice were at least 3 months old. The CT (UBC- $B d n f$ iKO No TAM, $n=4$ : two males, two females; UBC- $B d n f \mathrm{iKO}, n=8$ : four males, four females) or the GSP (UBC- $B d n f$ iKO No TAM, $n=5$ : two females, three males; UBC- $B d n f$ $\mathrm{iKO}, n=5$ : two males, three females) nerve was labeled as described for the terminal field labeling procedure, with the exception that the $3 \mathrm{kDa}$ tetramethylrhodamine dextran was chosen as the only tracer because it did not require further processing for visualization. This allowed imaging the entire intact ganglion, thereby allowing us to count all labeled cells. Petrosal ganglia (UBC-Bdnf iKO No TAM, $n=4$ : two males, two females; UBC- $B d n f$ iKO, $n=9$ : six males, three females) were also labeled by way of the IX, using the tetramethylrhodamine tracer. Ganglia collection, processing, and imaging were similar to that described by Sun et al. $(2015,2017)$.

CT nerve neurophysiology. All animals used for taste recording experiments were at least 3 months old. Mice (controls, $n=8$ : four males, four females; K14- $B d n f$ iKO No TAM, $n=6$ : three males, three females; K14- $B d n f \mathrm{iKO}, n=5$ : two males, three females; UBC- $B d n f \mathrm{iKO}$ No TAM, $n=6$ : three males, three females; UBC-Bdnf $\mathrm{iKO}, n=6$ : four males, two females) were anesthetized as described for the fluorescent anterograde nerve labeling procedure. Procedures for recording taste responses from the CT and data analyses were as described by Sun et al. $(2015,2017)$ and are only briefly described here. Taste responses were recorded to an ascending concentration series of $0.05,0.1,0.25$, and $0.5 \mathrm{M} \mathrm{NaCl} ; 10,20$, and $50 \mathrm{~mm}$ citric acid; $0.1,0.25,0.5$, and $1.0 \mathrm{M}$ sucrose; and 10, 20, 50, and $100 \mathrm{~mm}$ quinine hydrochloride. All chemicals were reagent grade and prepared in artificial saliva (Hellekant et al., 1985). Each concentration series was bracketed by applications of $0.5 \mathrm{M} \mathrm{NH}_{4} \mathrm{Cl}$ to monitor the stability of each preparation and for normalizing taste responses. Solutions were applied to the tongue in $5 \mathrm{ml}$ aliquots with a syringe and allowed to remain to the tongue for $\sim 20 \mathrm{~s}$. After each solution application, the tongue was rinsed with artificial saliva for $\geq 1$ min when the stimulus concentration was high. This period allows for full recovery of neural responses (i.e., the responses were not adapted by previous responses; Shingai and Beidler, 1985). CT responses were calculated as follows: the average voltage of the spontaneous activity that occurred for the $5 \mathrm{~s}$ before stimulus onset was subtracted from the average voltage that occurred from the period from the 5th to 15th second after stimulus application. Response magnitudes were then expressed as ratios relative to the mean of $0.5 \mathrm{M} \mathrm{NH}_{4} \mathrm{Cl}$ responses before and after stimulation. Whole-nerve response data were retained for analysis only when $0.5 \mathrm{M}$ $\mathrm{NH}_{4} \mathrm{Cl}$ responses that bracketed a concentration series varied by $<10 \%$. In addition, responses were recorded to the $\mathrm{NaCl}$ concentration series in the epithelial sodium channel blocker amiloride (50 $\mu \mathrm{M}$; Benos, 1982). Rinses during this series were with amiloride.

\section{Experimental design and statistical analysis}

qPCR results. Means of normalized $B d n f$ expression levels were compared between K14-Bdnf iKO No TAM and K14-Bdnf iKO mice for anterior tongue, geniculate ganglion, and NST with a two-tailed unpaired $t$ test. The same analysis was also done between UBC-Bdnf $\mathrm{iKO}$ No TAM and UBC-Bdnf $\mathrm{iKO}$ mice.

Terminal field volumes. The mean $( \pm \mathrm{SEM})$ was calculated for the total CT, GSP, and IX nerve terminal field volumes, for their overlapping field volumes, and for terminal field volumes within the four defined dorsoventral zones. We first analyzed the terminal fields by comparing volumes among the three nerves (i.e., IX, CT, and GSP). We then separately analyzed terminal fields by comparing the overlaps among the nerves (e.g., CT with GSP). This was done through a two-way ANOVA (SPSS; RRID:SCR_002865; experimental group $\times$ nerve/overlap), with post hoc pairwise comparisons done with Bonferroni's post-tests (SPSS). For all statistical tests, we considered $p$ values $\leq 0.05$ to be significant.

Ganglion cell counts. Ganglion cell numbers for the CT, GSP and IX were compared among controls, K14- $B d n f$ iKO mice, and UBC- $B d n f$ iKO mice and analyzed with a two-way ANOVA (SPSS; experimental group $\times$ nerve), with post hoc pairwise comparisons done with Bonferroni's post-tests (SPSS). For all statistical tests, we considered $p$ values $\leq 0.05$ to be significant.

Whole-nerve taste Responses. A two-way repeated-measures ANOVA (SPSS) was used to compare mean ( \pm SEM) relative CT responses (compared with $0.5 \mathrm{M} \mathrm{NH}_{4} \mathrm{Cl}$ responses) initially among control, K14-Bdnf iKO No TAM, and K14-Bdnf iKO mice and then among control, UBC$B d n f$ iKO No TAM, and UBC-Bdnf $\mathrm{iKO}$ mice to a concentration series of $\mathrm{NaCl}$, sucrose, citric acid, and quinine hydrochloride (each 3 groups $\times 3$ or 4 concentrations; post hoc pairwise comparisons done with Bonferroni's post-tests). For all statistical tests, we considered $p$ values $\leq 0.05$ to be significant.

\section{Results}

Bdnf mRNA expression is selectively reduced in the tongue of $\mathrm{K} 14-\mathrm{Bdnf} \mathrm{iKO}$ mice and reduced in the tongue, geniculate ganglion, and NST in UBC-Bdnf iKO mice after tamoxifen K14-Bdnf $i$ KO mice

$B d n f$ expression in mice that had the gene deleted on one allele throughout development (K14- $B d n f$ iKO No TAM mice) showed an approximate $32 \%$ decrease in the amount of $B d n f$ expression in tongue compared with the control standard (control, 1.0; Fig. $1 A)$. By contrast, tamoxifen administration at adulthood in K14$B d n f \mathrm{iKO}$ mice resulted in an $88 \%$ decrease in $B d n f$ expression in the tongue at 2 months after the treatment compared with controls (Fig. 1A). This decrease in $B d n f$ expression was significantly more than found in K14- $B d n f$ iKO No TAM mice $\left(t_{(11)}=19.7\right.$; $p=0.0001)$. The amount of $B d n f$ expression in the geniculate ganglion for K14-Bdnf iKO No TAM and K14-Bdnf $\mathrm{iKO}$ mice decreased $\sim 30$ and $27 \%$ below controls, respectively (Fig. 1B). A similar pattern of expression was apparent in the NST. In this structure, the amount of $B d n f$ expression decreased 30 and $23 \%$ in K14-Bdnf iKO No TAM and K14-Bdnf iKO mice, respectively, from the control standard (Fig. 1C). There were no significant differences in expression between these two groups for geniculate ganglion or NST $\left(t_{(8)}=0.2, p=0.87\right.$ and $t_{(8)}=0.6, p=0.56$, respectively). Therefore, $B d n f$ expression levels were dramatically and selectively reduced in the tongue at adulthood.

\section{$U B C-B d n f$ iKO mice}

Our goal for experiments in this group of mice was to inducibly reduce $B d n f$ expression significantly at adulthood in all tissues. We found, for all three tissues, that $B d n f$ expression was drastically decreased in UBC-Bdnf $\mathrm{iKO}$ mice at 2 months after tamoxifen. In the tongue, UBC- $B d n f$ iKO No TAM mice showed a decrease of $\sim 34 \%$ compared with controls, whereas there was a $90 \%$ decrease in Bdnf expression in UBC- $B d n f$ iKO mice com- 

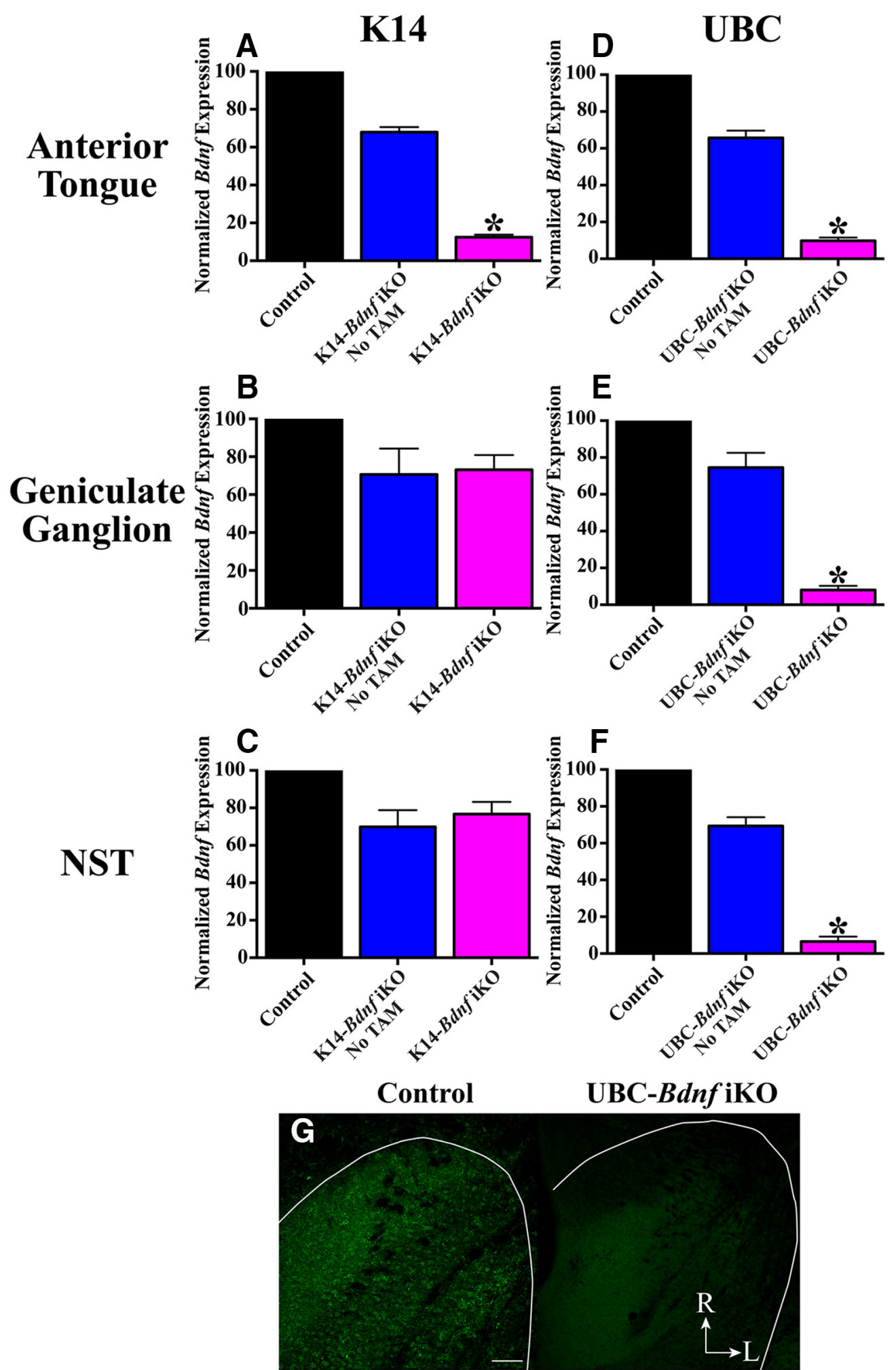

Figure 1. $\quad \boldsymbol{A}-\boldsymbol{F}, \mathrm{Mean}( \pm \mathrm{SEM})$ normalized expression levels of $B d n f$ in the anterior tongue $(\boldsymbol{A})$, geniculate ganglion $(\boldsymbol{B})$, and NST $(\boldsymbol{C})$ in control (black bars), K14-Bdnf iKO No TAM (blue bars), and K14-BdnfiKO (magenta bars) mice and mean ( \pm SEM) normalized expression levels of $B d n f$ in the anterior tongue ( $\boldsymbol{D})$, geniculate ganglion (E), and NST (F) in control (black bars), UBC-BdnfiKO No TAM (blue bars), and UBC-Bdnf iKO (magenta bars) mice. Means were calculated relative to the respective expression levels in control mice. The expression ratio of 1.0 represents the control mean. Asterisks denote significantly less than the respective No TAM group $(p<0.05)$. G, Photomicrograph of a horizontal section through the anterior portion of the NST showing immunohistochemical labeling to anti-BDNF in a control (left) and a UBC-Bdnf iKO (right) mouse. Scale bar, $100 \mu \mathrm{m}$. R, Rostral; L, lateral. White lines in $\mathrm{G}$ denote outlines of NST.

pared with controls (Fig. 1D). The mean expression in the anterior tongue was significantly different between UBC-Bdnf iKO No TAM and UBC-Bdnf iKO mice (Fig. $1 D ; t_{(10)}=13.0 ; p=$ 0.0001). Similarly, the amount of $B d n f$ expression was succes- sively decreased in UBC-Bdnf iKO No TAM and in UBC-Bdnf iKO mice in both the geniculate ganglion and NST (Fig. $1 E, F$ ). Specifically, Bdnf expression decreased by 25 and $92 \%$ in the geniculate ganglia of UBC-Bdnf iKO No TAM and UBC-Bdnf 
$\mathrm{iKO}$ mice, respectively (comparison between groups: $t_{(5)}=9.4$; $p=0.0002$ ), and decreased by 30 and $94 \%$ in the NST of UBC$B d n f$ iKO No TAM and UBC- $B d n f$ iKO mice, respectively (comparison between groups: $\left.t_{(6)}=9.4 ; p=0.0001\right)$.

The differences in expression of $B d n f$ in the geniculate ganglion and NST between K14- $B d n f \mathrm{iKO}$ and UBC-Bdnf $\mathrm{iKO}$ mice can be explained by the different sites where $B d n f$ was deleted. Unlike K14- $B d n f$ iKO mice, where $B d n f$ was only deleted in the tongue, it was deleted in tongue, geniculate ganglion, and NST in UBC- $B d n f$ iKO mice. All three of these structures normally express $B d n f$ (Conner et al., 1997; Meng et al., 2015). We also found $B d n f$ expression in the NST at locations corresponding to the gustatory recipient zone for the three nerves (data not shown). Although we did not measure $B d n f$ expression in the petrosal ganglion (cell soma of the IX), these cells also express $B d n f$ (Brady et al., 1999). Thus, it is likely that $B d n f$ was deleted in these cells also.

\section{The rostral NST in UBC-Bdnf iKO mice shows less immunoreactivity to BDNF antibodies than in control mice} To test whether our Bdnf expression data from the NST were reflected in immunoreactivity for BDNF, we qualitatively examined immune-stained tissue in two control and two UBC-Bdnf iKO mice. Figure $1 G$ shows that there was robust immunopositive labeling in the rostral NST in control mice. The NST in $\mathrm{UBC}-B d n f \mathrm{iKO}$ mice lack the punctate labeling seen in controls and only showed background staining (Fig. $1 G$ ). Interestingly, there was noticeably more immune-positive staining in the rostral NST in controls compared with adjacent regions in the brainstem (Fig. 1G).

Total terminal field volumes are enlarged differentially in mice where Bdnf expression was reduced in the tongue or in all tissues

\section{Control mice}

Similar to what was found for control mice in a study where $B d n f$ was overexpressed in the tongue (Sun et al., 2015), the total terminal field volumes for all three nerves (IX, CT, and GSP) in controls were similar to each other (Fig. 2A, black bars). Moreover, the total terminal field size for the double (CT with GSP, IX with GSP, IX with CT) and the triple (CT with GSP with IX) terminal field overlaps were similar in size to control mice in the study by Sun et al. (2015; Fig. 2A, black bars).

\section{Bdnf iKO No TAM mice}

As noted previously, two additional control groups had all of the transgenes for K14-Bdnf $\mathrm{iKO}$ or for UBC-Bdnf $\mathrm{iKO}$ but did not receive administration of tamoxifen (No TAM). The terminal field volumes for these two groups were similar to each other $(p>0.05)$; therefore, we pooled these data into one control group denoted as $B d n f$ iKO No TAM mice (Fig. $2 A$ ). This group represents the effects of the $B d n f$ knock-out on a single allele throughout development. For all total terminal field volumes, the $B d n f$ iKO No TAM mice were statistically similar to littermate controls that lacked all of the transgenes (Fig. 2A, blue bars; Table 1 ; all post-tests $p>0.1$ ).

Total terminal field volumes in mice where Bdnf expression was reduced in the tongue

In contrast to control mice, the CT and GSP terminal field volumes in mice in which $B d n f$ expression was significantly reduced in the tongue were greater than found for the IX. Moreover, the total terminal field volumes for the CT and GSP in K14-Bdnf iKO mice were 48 and $81 \%$ greater, respectively, than the total terminal field volumes found in controls (Fig. 2A, Table 1; post-test $p=0.004$ and 0.0001 , respectively) and 61 and $86 \%$ greater, respectively, than in $B d n f$ iKO No TAM mice (Fig. $2 A$, Table 1; post-test $p=0.003$ and 0.0001 , respectively). Furthermore, the CT with GSP overlapping field volumes in K14-Bdnf iKO mice was $69 \%$ greater than in control mice (Table 1 ; post-test $p=$ 0.0001 ) and $105 \%$ greater than in $B d n f$ iKO No TAM mice (Table 1 ; post-test $p=0.0001$ ). All other terminal field sizes (IX and other overlapping fields) in $\mathrm{K} 14-B d n f \mathrm{iKO}$ mice were similar to those in control and in $B d n f$ iKO No TAM mice (Fig. $2 A$, Table 1; post-test $p$ value range, $0.16-1.00)$.

\section{Total terminal field volumes in mice where Bdnf expression was reduced in all cells}

In contrast to mice in which $B d n f$ expression was significantly reduced only in the tongue at adulthood, large-scale increases in total terminal field volumes were apparent when $B d n f$ expression was reduced in all cells. Specifically, the total terminal field size for the IX, CT, and GSP nerves in UBC-Bdnf iKO mice were 121, 100 , and $77 \%$ greater than the respective terminal field volumes in control mice (Fig. 2A, Table 1; post-test $p=0.0001,0.0001$, and 0.002 , respectively) and 81,118 , and $83 \%$ greater than the respective terminal field volumes in $B d n f \mathrm{iKO}$ No TAM mice (Fig. $2 A$, Table 1; post-test $p=0.0001,0.0001$, and 0.001 , respectively). Moreover, all of the overlapping fields were approximately two times the total volume of the respective fields of overlap found in control mice (Fig. $2 A$, Table 1; post-test $p$ value range, $0.01-$ 0.0001 ) and 2-2.5 times the total volume of the respective fields of overlap found in Bdnf iKO No TAM mice (see Fig. 5, Table 1; post-test $p$ value range, $0.001-0.0001$ ).

\section{Total terminal field volume differences between K14-Bdnf iKO and UBC-Bdnf iKO mice}

To further examine the role of BDNF in the organization of terminal fields in the rostral NST, we examined differences between the two tamoxifen-treated groups. As seen in Figure $2 A$, the terminal field volumes for the IX and CT in mice in which $B d n f$ expression was reduced in all cells were significantly larger (IX, $71 \%$; CT, 36\%) than in mice where $B d n f$ expression was reduced only in the tongue (Table 1 ; post-test $p=0.0001$ ). As could be expected from the terminal field volumes of the nerves, the IX with CT overlapping field volumes in UBC- $B d n f$ iKO mice were nearly two times greater than that in K14- $B d n f$ iKO mice (Fig. $2 A$, Table 1; post-test $p=0.0001)$. No other group-related comparisons were significant (post-test $p$ value range, $0.19-1.00$ ).

\section{Total terminal field volume summary}

Removal of $B d n f$ from the tongue at adulthood had effects on the total terminal field volumes of the CT and GSP within 2 months after tamoxifen administration. In contrast, removal of $B d n f$ from all cells had a global effect on all terminal field volumes by significantly increasing them relative to controls. Moreover, the lack of the $B d n f$ gene on one allele throughout development had no effect on total terminal field volumes.

\section{Terminal field volumes and densities within NST dorsoventral zones}

Expansion of the terminal field volumes occurs in multiple dorsoventral zones

To test whether the terminal fields of experimental mice were reorganized in one or more dorsoventral zones in the NST, we 

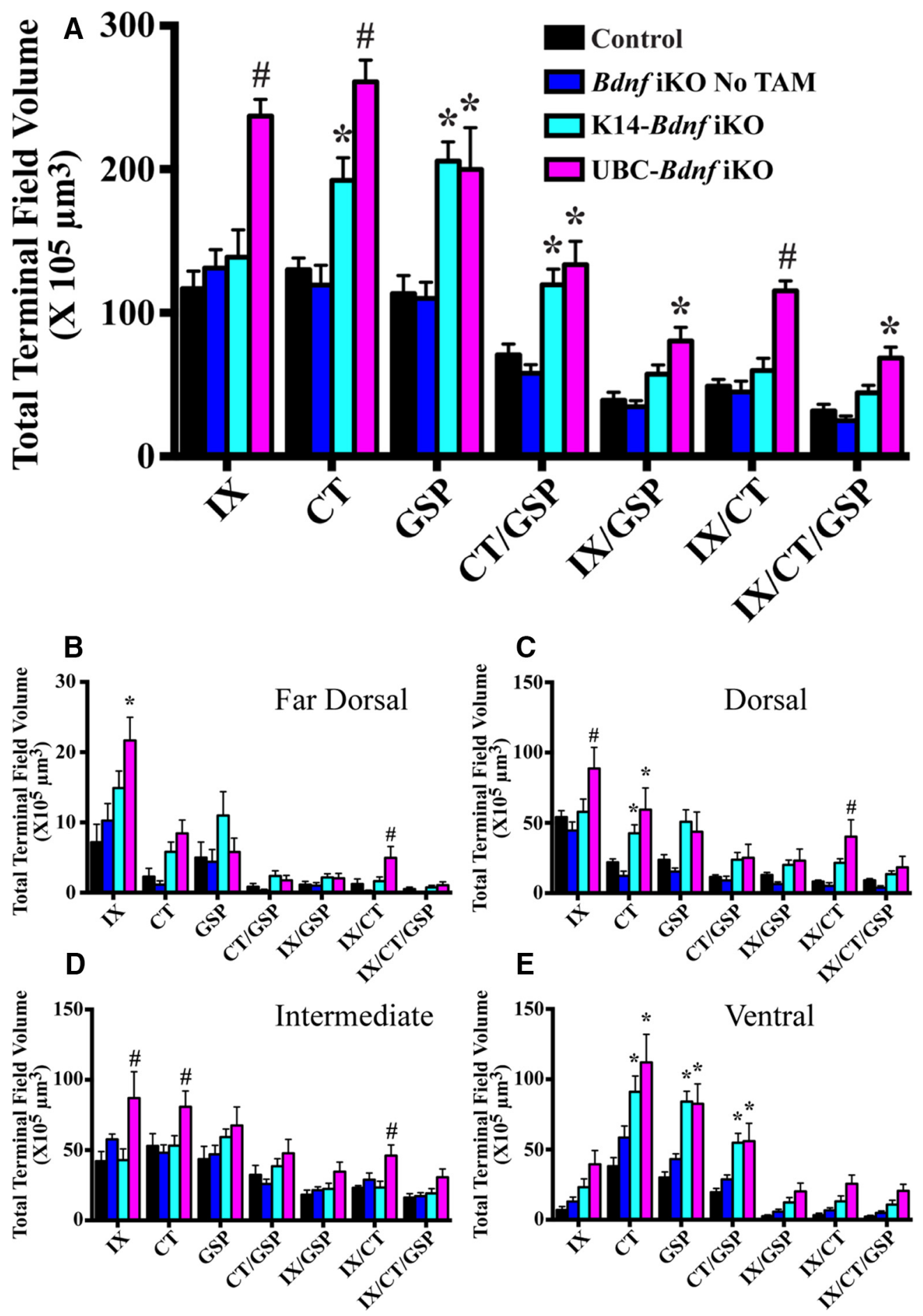

Figure 2. $A$, Mean ( \pm SEM) total terminal field volumes for the IX, CT, and GSP nerves and their double and triple overlaps of terminal fields in control (black bars), BdnfiKO No TAM (blue bars), K14-BdnfiKO (teal bars), and UBC-BdnfiKO (magenta bars) mice. $\boldsymbol{B}-\boldsymbol{E}$, Mean ( \pm SEM) terminal field volumes for the IX, CT, and GSP nerves and their double and triple overlaps of terminal fields in the far dorsal zone $(\boldsymbol{B})$, dorsal zone $(\boldsymbol{C})$, intermediate zone $(\boldsymbol{D})$, and ventral zone $(\boldsymbol{E})$ of the NST in the same animals shown in $\boldsymbol{A}$. "Significantly different from all other three groups; ${ }^{*}$ Significantly different from control and BdnfiKO No TAM mice.

examined differences in terminal field volumes in each of the four dorsal to ventral zones described previously.

Far dorsal zone. For all groups, this zone contained the least volume of terminal field labeling (Fig. $2 B$; note difference in $y$-axis compared with Fig. 2C-E). Moreover, the far dorsal zone had more IX terminal field labeling than that for the CT and GSP (Fig. 2B). However, the only significant differences in terminal field volumes among groups were that the IX terminal field volume in UBC-Bdnf
iKO was approximately three and two times greater than controls and BdnfiKO No TAM mice, respectively (Fig. 2B, Table 1; post-test $p=0.0001$ and 0.005 , respectively). For overlapping fields, the IX with CT overlap volume for UBC-BdnfiKO mice was 4 times greater than in controls (post-test $p=0.0001$ ), 5 times greater than in $B d n f$ iKO No TAM mice (post-test $p=0.0001$ ), and 1.6 times greater than in K14-Bdnf iKO mice (post-test $p=0.001$; Fig. $2 B$, Table 1 ). No other significant differences were found for this zone. 


\section{Table 1. ANOVA results}

\begin{tabular}{|c|c|c|c|c|}
\hline Measure & Factor & df & $F$ & $\overline{\text { Significance }}$ \\
\hline Total volume-single nerves & Group & 3,63 & 35.1 & 0.0001 \\
\hline Total volume-single nerves & Group $\times$ nerve & 6,63 & 2.9 & 0.02 \\
\hline Total volume-overlap & Group & 3,84 & 45.3 & 0.0001 \\
\hline Total volume-overlap & Group $\times$ nerve & 9,84 & 2.5 & 0.02 \\
\hline Far dorsal volume-single nerves & Group & 3,63 & 7.7 & 0.0001 \\
\hline Far dorsal volume-single nerves & Group $\times$ nerve & 6,63 & 1.7 & 0.12 \\
\hline Far dorsal volume-overlap & Group & 3,84 & 9.8 & 0.0001 \\
\hline Far dorsal volume-overlap & Group $\times$ nerve & 9,84 & 2.2 & 0.03 \\
\hline Dorsal volume-single nerves & Group & 3,63 & 14.2 & 0.0001 \\
\hline Dorsal volume-single nerves & Group $\times$ nerve & 6,63 & 1.1 & 0.39 \\
\hline Dorsal volume-overlap & Group & 3,84 & 16.2 & 0.0001 \\
\hline Dorsal volume-overlap & Group $\times$ nerve & 9,84 & 1.1 & 0.39 \\
\hline Intermediate volume-single nerves & Group & 3,63 & 6.8 & 0.0001 \\
\hline Intermediate volume-single nerves & Group $\times$ nerve & 6,63 & 1.2 & 0.34 \\
\hline Intermediate volume-overlap & Group & 3,84 & 9.9 & 0.0001 \\
\hline Intermediate volume-overlap & Group $\times$ nerve & 9,84 & 0.6 & 0.76 \\
\hline Ventral volume-single nerves & Group & 3,63 & 22.9 & 0.0001 \\
\hline Ventral volume-single nerves & Group $\times$ nerve & 6,63 & 1.7 & 0.13 \\
\hline Ventral volume-overlap & Group & 3,84 & 22.8 & 0.0001 \\
\hline Ventral volume-overlap & Group $\times$ nerve & 9,84 & 1.9 & 0.06 \\
\hline Ganglion count & Group & 2,40 & 0.7 & 0.52 \\
\hline Ganglion count & Nerve & 2,40 & 99.9 & 0.0001 \\
\hline Ganglion count & Group $\times$ nerve & 4,40 & 0.3 & 0.89 \\
\hline \multicolumn{5}{|l|}{ K14-BdnfiKO mice } \\
\hline $\mathrm{NaCl}$ taste response & Group & 2,16 & 0.8 & 0.47 \\
\hline $\mathrm{NaCl}$ taste response & Group $\times$ concentration & 6,48 & 0.1 & 0.99 \\
\hline $\mathrm{NaCl}$ after amiloride & Group & 2,14 & 0.5 & 0.65 \\
\hline $\mathrm{NaCl}$ after amiloride & Group $\times$ concentration & 6,42 & 2.8 & 0.02 \\
\hline Citric acid taste response & Group & 2,18 & 1.2 & 0.31 \\
\hline Citric acid taste response & Group $\times$ concentration & 4,36 & 2.7 & 0.05 \\
\hline Sucrose taste response & Group & 2,19 & 0.2 & 0.83 \\
\hline Sucrose taste response & Group $\times$ concentration & 6,57 & 0.9 & 0.47 \\
\hline Quinine taste response & Group & 2,18 & 0.6 & 0.55 \\
\hline Quinine taste response & Group $\times$ concentration & 6,54 & 0.6 & 0.72 \\
\hline \multicolumn{5}{|l|}{ UBC-Bdnf iKO mice } \\
\hline $\mathrm{NaCl}$ taste response & Group & 2,18 & 0.4 & 0.69 \\
\hline $\mathrm{NaCl}$ taste response & Group $\times$ concentration & 6,54 & 0.6 & 0.75 \\
\hline $\mathrm{NaCl}$ after amiloride & Group & 2,16 & 3.5 & 0.06 \\
\hline $\mathrm{NaCl}$ after amiloride & Group $\times$ concentration & 6,48 & 1.6 & 0.18 \\
\hline Citric acid taste response & Group & 2,21 & 0.6 & 0.54 \\
\hline Citric acid taste response & Group $\times$ concentration & 4,42 & 1.9 & 0.12 \\
\hline Sucrose taste response & Group & 2,17 & 0.1 & 0.92 \\
\hline Sucrose taste response & Group $\times$ concentration & 6,51 & 0.6 & 0.72 \\
\hline Quinine taste response & Group & 2,19 & 0.0 & 0.99 \\
\hline Quinine taste response & Group $\times$ concentration & 6,57 & 0.6 & 0.70 \\
\hline
\end{tabular}

The table shows the specific measure tested, the factor, degrees of freedom (df), F value, and significance of each ANOVA statistical test presented in Results. They appear in the order presented in Results.

Dorsal zone. As in the far dorsal zone, the IX terminal field volume was 1.6 and 2 times greater than in controls and $B d n f \mathrm{iKO}$ No TAM mice, respectively (post-test $p=0.03$ and 0.002 , respectively). It was also 1.5 times greater than in $\mathrm{K} 14-B d n f \mathrm{iKO}$ mice (Fig. $2 C$, Table 1; post-test $p=0.05$ ). Unlike that seen in the far dorsal zone, the CT terminal field volume in K14-Bdnf $\mathrm{iKO}$ and $\mathrm{UBC}-B d n f \mathrm{iKO}$ mice were greater than the two control groups. For K14- $B d n f$ iKO mice, the CT terminal field volume was $\sim 2$ and 3.5 times greater than in controls and in $B d n f$ iKO No TAM mice, respectively (Fig. $2 C$, Table 1 ; post-test $p=0.05$ and 0.02 , respectively). For UBC- $B d n f$ iKO mice, the $\mathrm{CT}$ terminal field volume was $\sim 2.7$ and 4.8 times greater than in controls and in $B d n f$ iKO No TAM mice, respectively (Fig. 2C, Table 1; post-test $p=0.01$ and 0.001 , respectively). Finally, the terminal field overlap volume between the IX and CT for UBC- $B d n f \mathrm{iKO}$ mice was 4.8 times greater than in controls (post-test $p=0.0001$ ), 7.7 times greater than in $B d n f$ iKO No TAM mice (post-test $p=0.0001$ ), and 1.9 times greater than in $\mathrm{K} 14-B d n f \mathrm{iKO}$ mice (post-test $p=$ 0.03; Fig. 2C, Table 1). No other significant differences were found for this zone.

Intermediate zone. This zone had similar proportions of terminal field labeling for the IX, CT, and GSP within each of the four groups (Fig. 2D). Moreover, the pattern of terminal field volume differences described for the dorsal zone occurred here also. That is, group-related differences in terminal field volumes were apparent for the IX, CT, and IX with CT terminal field overlap (Fig. 2D). The only difference between the two zones was that the CT volume in UBC- $B d n f \mathrm{iKO}$ mice was different than all of the other three groups (Fig. 2D). In this zone, the terminal field volume for the IX in UBC-Bdnf iKO mice was $\sim 1.4-2$ times greater than in the other three groups (Fig. 2D, Table 1; post-test $p$ value range, $0.006-0.05)$, the CT was $\sim 1.5$ times greater than in the other three groups (Fig. $2 D$, Table 1; post-test $p$ value range, 0.01-0.05), and the IX with CT overlap terminal volume was $\sim 2$ times greater than in the other three groups (Fig. $2 D$, Table 1; post-test $p$ value range, $0.07-0.04)$. No other significant differences were found for this zone.

Ventral zone. For all groups, this zone contained the least amount of IX terminal field volume, and there were no significant differences among groups for the IX. Thus, the group-related differences in this zone were confined to the CT, GSP, and CT with GSP overlap terminal field volumes (Fig. 2E). For the CT, GSP, and CT with GSP overlaps, both K14-Bdnf iKO and UBC$B d n f$ iKO mice had significantly greater (1.5-3 times) terminal field volumes than in controls (Fig. $2 E$, Table 1; post-test $p$ value range, $0.0001-0.03$ ) and $B d n f$ iKO No TAM mice (Fig. 2E, Table 1 ; post-test $p$ value range, $0.0001-0.02)$. No other significant differences were found for this zone.

\section{Summary of terminal field volumes across zones}

Group-related differences for terminal field volumes occurred through all dorsoventral zones, but less so in the far dorsal zone because of the relatively small amount of label for all nerves. Moreover, UBC-Bdnf $\mathrm{iKO}$ mice showed the most differences in terminal field volumes from controls and occurred in all three nerves distributed among all four zones.

Group-related terminal field changes occur in the densest regions of the NST normally occupied in controls

To test whether the group-related differences in terminal field volumes represent a spatial reorganization of the respective terminal fields, we qualitatively examined representative photomicrographs and examined density plots of the IX, GSP, CT, and triple-overlap terminal field volumes in each zone for $B d n f \mathrm{iKO}$ No TAM, K14-Bdnf iKO, and UBC-Bdnf iKO mice (Fig. 3). For clarity, we chose not to show data from control mice in Figure 3 because they were qualitatively similar to $B d n f$ iKO No TAM mice.

Far dorsal zone. The terminal field volume differences shown in Figure $2 B$ were reflected in photomicrographs of terminal fields from this zone (Fig. $3 A$ ). That is, the largest amount of IX labeling is evident in the photomicrograph for the UBC-Bdnf $\mathrm{iKO}$ mouse, followed by labeling in the $\mathrm{K} 14-B d n f \mathrm{iKO}$, and finally in the $B d n f$ iKO No TAM mouse. Moreover, it appears that the fields for the IX, GSP, and CT were not drastically rearranged in the two experimental groups. That is, the same pattern of innervation occurred among the $B d n f$ iKO No TAM, K14-Bdnf $\mathrm{iKO}$, and $\mathrm{UBC}-B d n f \mathrm{iKO}$ mice (Fig. $3 A$ ) and is reflected in the group measures of terminal field densities within the NST (Fig. $3 B$ ). For the 


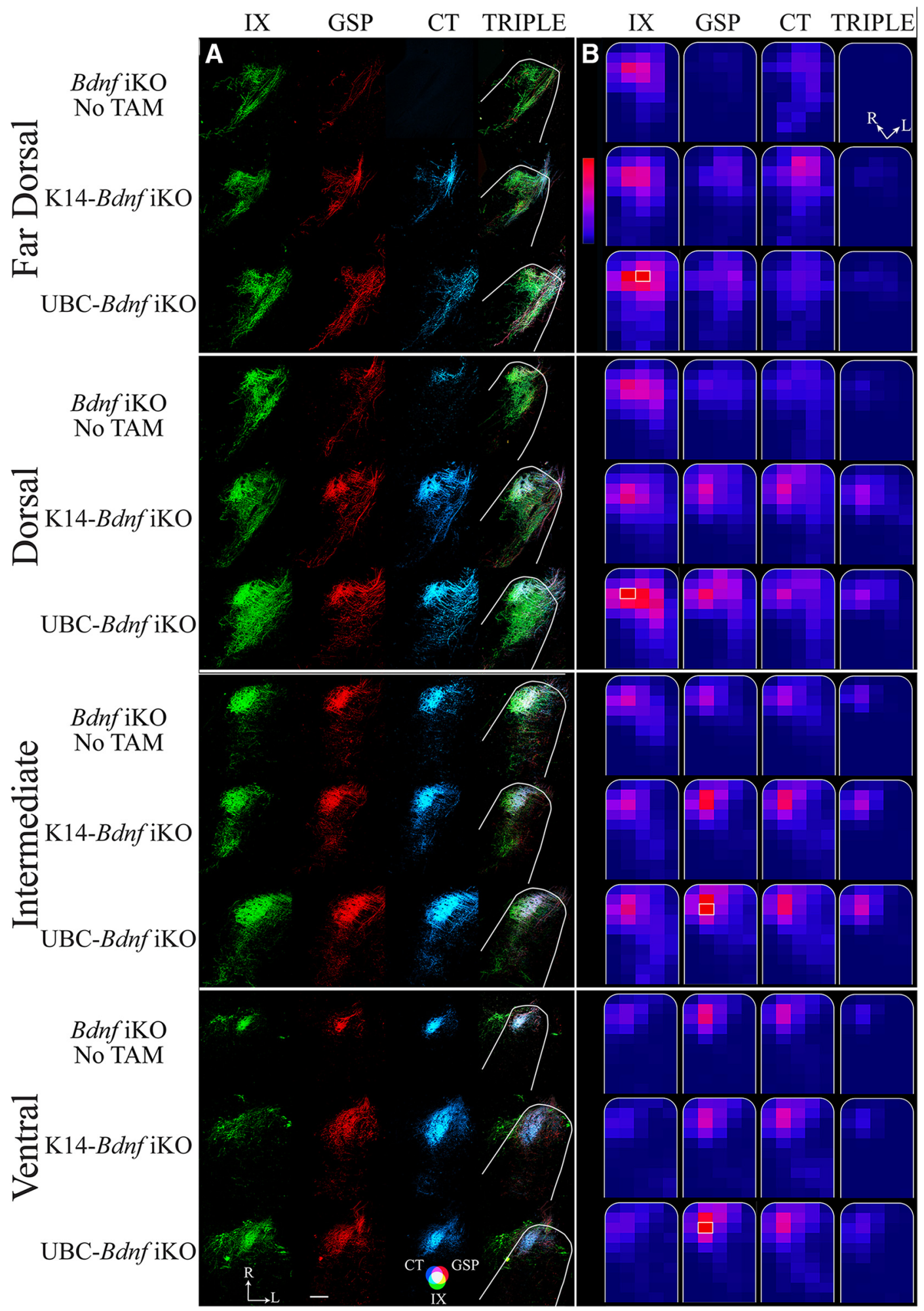

Figure 3. A, Horizontal sections of labeled terminal fields of IX (green), GSP (red), CT (blue), and merged images of all three nerves (TRIPLE) for a BdnfiKO No TAM (top row for each zone), a K14-Bdnf iKO (middle row of each zone), and a UBC-BdnfiKO (bottom row of each zone) mouse. For the triple photomicrographs, the CT-GSP overlap is shown as magenta, the IX-GSP overlap is shown as yellow, the IX-CT overlap is shown as blue-green, and the (T-GSP-IX terminal field overlap is shown as white (refer to the color guide in the CT column in the ventral zone of the UBC-BdnfiK0 mouse).Scale bar, $200 \mu \mathrm{m}$. R, Rostral; L, lateral. $B$, Heat maps showing the terminal field densities (volume of terminal field label in a division/total volume of the division) for IX, CT, and GSP nerves and for the triple overlap of all three nerve terminal fields (TRIPLE) for Bdnf KKO No TAM mice (top row for each zone), K14-BdnfiKO mice (middle row of each zone), and UBC-BdnfiKO mice (bottom row of each zone). The NST (borders shown in white) has been rotated so that the solitary tract is oriented vertically [see Materials and Methods and rostral (R) and lateral (L) orientations in triple overlap]. The NST for each zone is divided into a maximum of $100 \times 100$ pixel divisions for each optical image (see Materials and Methods). The colors for the heat map of densities are on the relative scale shown for the far dorsal zone, with $0 \%$ of maximum density noted as dark blue and $100 \%$ noted as red. This relative scale was applied to each of the four zones; therefore, the maximum density was obtained from all of the divisions from Bdnf iKO No TAM, K14-BdnfiK0, and UBC-BdnfiKO mice for the far dorsal zone and similarly for the dorsal, intermediate, and ventral zones. The division representing $100 \%$ (brightest red) for each zone is shown by a white border around the respective $100 \times 100$ pixel division (e.g., contained in the IX terminal field of UBC-Bdnf iKO mice in the far dorsal zone). 
density measures shown in Figure $3 B$, the primary characteristic that distinguishes differences among the three groups was the amount of label within specific locations containing the densest label within each group (Fig. 3B). The densest region of terminal fields (or "core" of labeling) for each group was approximately at the same location across the three groups for each nerve, but with the densest label across all nerves and for the triple overlap located at the core region for the IX in UBC-Bdnf iKO mice (Fig. $3 B$, white rectangle).

Dorsal zone. As noted for the far dorsal zone, the terminal field distribution was similar among groups for each nerve, and differences in amount of labeling in the same location is consistent with the differences in terminal field volumes (Fig. $3 A$ ). In this zone, however, there was also an extension of terminal field beyond the densest projection in the K14- $B d n f \mathrm{iKO}$ and UBC- $B d n f \mathrm{iKO}$ mice compared with controls. This is especially apparent in the density representations between $B d n f$ iKO No TAM and UBC- $B d n f \mathrm{iKO}$ mice (Fig. $3 B$ ). As seen in the far dorsal zone, the densest region among all nerves and across all three groups was for the IX in UBC-Bdnf iKO mice (Fig. $3 B$ ).

Intermediate zone. The photomicrographs from this zone clearly shows a greater amount of IX, GSP, and CT labeling in UBC- $B d n f$ iKO mice compared with $B d n f$ iKO No TAM mice. However, as in the other zones, the location of labels was similar among the three groups (Fig. $3 A$ ). The amount of terminal field labeling in the K14-Bdnf $\mathrm{iKO}$ mouse was intermediate to the other two groups (Fig. 3A). These terminal field characteristics are also evident in the density measurements (Fig. $3 B$ ). Unlike the other zones, the location of the greatest amount of labeling occurred for the GSP in UBC-Bdnf iKO mice, although it was not much greater than the respective location of CT label in UBC$B d n f$ iKO mice (Fig. 3B).

Ventral zone. Here, as shown in Figure $2 E$, there was relatively little terminal field label of the IX compared with GSP and CT labels for all groups. Also, whereas there was more terminal field volume for the GSP and CT in K14-Bdnf $\mathrm{iKO}$ and UBC-Bdnf $\mathrm{iKO}$ mice compared with that in $B d n f$ iKO No TAM mice (Fig. $2 E$ ), the photomicrographs (Fig. 3A) and density analyses (Fig. 3B) indicate that the difference in volume is likely caused by spread of label beyond the densest region of the NST. That is, similar amounts of labeling within each nerve and for the triple overlap occurred among all groups in the core region, but with more spread of label laterally in $\mathrm{K} 14-B d n f \mathrm{iKO}$ and $\mathrm{UBC}-B d n f \mathrm{iKO}$ mice compared with $B d n f$ iKO No TAM mice (Fig. $3 B$ ). As noted for the intermediate zone, the location of densest labeling among all nerves and groups in this zone occurred for the GSP in UBC$B d n f$ iKO mice (Fig. 3B).

\section{More terminal field labeling is also seen in coronal sections from UBC-Bdnf iKO mice}

Figure 4 shows coronal sections of terminal fields of the three nerves (Fig. 4, $A, C$, and $E$, for the IX, GSP, and CT, respectively, in a UBC- $B d n f$ iKO No TAM mouse; $B, D$, and $F$, for the IX, GSP, and $C T$, respectively, in a UBC- $B d n f \mathrm{iKO}$ mouse) and their triple overlap (Fig. $4 G$ in a UBC- $B d n f$ iKO No TAM mouse, $H$ in a $\mathrm{UBC}-B d n f \mathrm{iKO}$ mouse). The section shown in Figure 4 is $\sim 200$ $\mu \mathrm{m}$ caudal to the anterior pole of the NST (Fig. 4I,J), which corresponds to the ventral zone of the NST noted in Figures 2 and 3. Here, there is little IX labeling compared with the GSP and CT in the UBC-Bdnf iKO No TAM mouse. By comparison, in the $\mathrm{UBC}-B d n f \mathrm{iKO}$ mouse shown, there is more IX labeling than would be expected from the terminal field volume data (Fig. 3D) and significant amounts of GSP and CT labels. The photomicro- graphs support the conclusions drawn from Figure 3 in that the primary group-related differences in GSP and CT terminal field labels occur in the core region of the fields and not a significant rearrangement of the fields.

\section{Ganglion cell counts of the CT, GSP, and IX}

Since BDNF plays a significant role in cell death of neurons (LeviMontalcini and Angeletti, 1963), we were interested to find whether loss of BDNF at adulthood resulted in a loss of neurons in the peripheral gustatory system. We counted the number of neurons in the geniculate ganglion that made up the CT and GSP nerves and in the petrosal ganglion that made up the IX.

In control mice, the number of geniculate ganglion cells that made up the CT were similar to those of the GSP (mean \pm SEM: CT, $210.0 \pm 18.3$; GSP, $196.0 \pm 11.0$ ), and both were significantly less than (Table 1 ; post-test $p=0.0001$ ) the number of petrosal ganglion cells that made up the IX (IX, $307.2 \pm 4.8$ ). The differences in cell numbers between the two ganglia likely relate to the size of the respective nerves, the relative greater field size of innervation by the IX, and relative differences in the type of sensory neurons (i.e., taste vs mechanosensory; Frank, 1991). The same pattern of ganglion cell numbers also occurred in K14- $B d n f \mathrm{iKO}$ mice (CT, 212.0 \pm 8.0; GSP, 190.2 \pm 7.3 ; IX, 311.7 \pm 12.7$)$ and in UBC-Bdnf iKO mice (CT, $193.8 \pm 7.6$; GSP, $191.0 \pm 9.1$; IX, $279.2 \pm 4.0$ ). For these experimental groups, the number of CT and GSP neurons were significantly less than the respective number of IX ganglion cell neurons (Table 1; post-test $p=0.0001$ ). There were no group-related differences in ganglion cell counts for any of the three nerves (Table $1 ; p$ value range, $0.57-1.000$ ). Therefore, deletion of $B d n f$ from either the tongue or from all cells at adulthood did not impact the number of ganglion cells that represent the CT, GSP, or IX.

\section{Neurophysiological taste responses in the CT}

To test whether the terminal field volume changes that we see here may be attributable to activity-dependent alterations in the function of at least one of these nerves, we recorded whole-nerve taste responses from the CT to an array of taste stimuli. Such a hypothesis is driven by the decreased innervation of taste buds on the anterior tongue when $B d n f$ was removed from the gustatory system at adulthood (Meng et al., 2015) and the demonstrated role of taste-elicited activity on the development and maintenance of these terminal fields (Skyberg et al., 2017; Sun et al., 2017). Surprisingly, there were no significant differences among taste responses among control, K14-Bdnf iKO No TAM, and K14-Bdnf iKO mice (Tables 1, 2; Fig. 5; post-test $p$ value range, $0.07-1.00 ; 52 \%$ of comparisons $p=1.00$ ) to any concentration of any stimulus. Similarly, with the exception of one post-test comparison, there were no significant differences among taste responses from control, UBC-Bdnf iKO No TAM, and UBC-Bdnf iKO mice (Tables 1, 2; Fig. 5; post-test $p$ value range, 0.04-1.001; $74 \%$ of comparisons $p=1.00$ ). The only significant difference between mean relative responses (total post-test comparisons, 114) was to $0.5 \mathrm{M} \mathrm{NaCl}$ after amiloride application. The responses in UBC- $B d n f$ iKO No TAM mice were significantly less than in controls (Fig. 5; post-test $p=0.04$ ). We do not regard this difference as biologically significant because it involves two control groups and the means are small, with a relatively small difference between them (Fig. 5). Collectively, these findings strongly indicate that the arborizations of the CT, particularly in the taste bud, do not translate to functional taste response changes in this nerve. 


\section{$\mathrm{UBC}-B d n f \mathrm{iKO}$ No TAM}
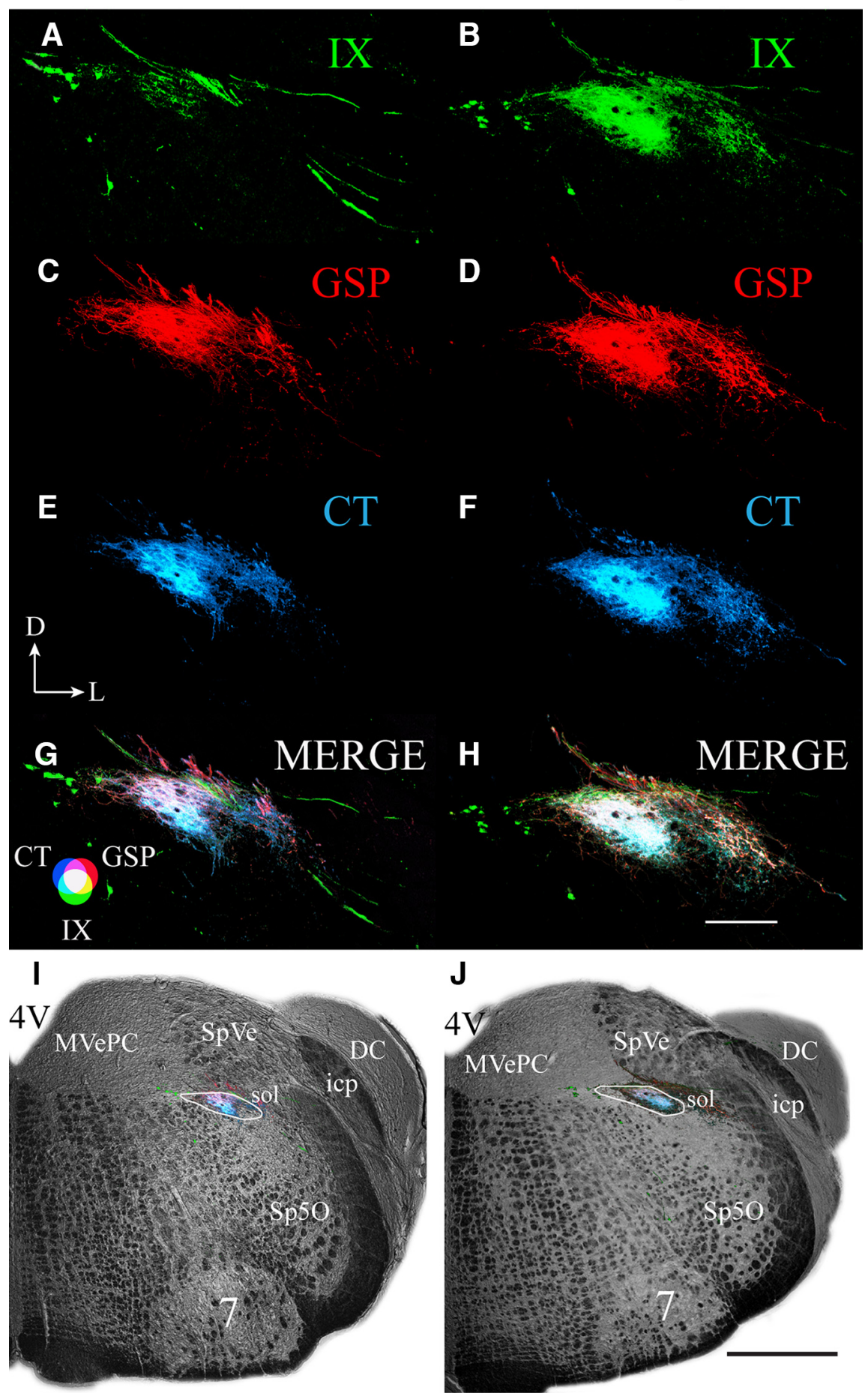

Figure 4. Coronal sections through the rostral/ventral NST showing the IXnerve terminal field (green; $A, B)$, GSP nerve terminal field labeling (red; $\boldsymbol{C}, \boldsymbol{D})$, CT nerve terminal field labeling (blue; $\boldsymbol{E}, \boldsymbol{F}$ ), and merged terminal fields $(\boldsymbol{G}, \boldsymbol{H})$ and the terminal fields in the right hemifield of medulla captured with transmitted light $(\boldsymbol{I}, \boldsymbol{J})$ in a $B d n f i K O \operatorname{NoTAM}(\boldsymbol{A}, \boldsymbol{C}, \boldsymbol{E}, \boldsymbol{F}, \boldsymbol{I})$ and a UBC-BdnfiKO $(\boldsymbol{B}, \boldsymbol{D}$, $\boldsymbol{F}, \boldsymbol{H}, \boldsymbol{J})$ mouse. The orientation of the sections is shown in $\boldsymbol{E}$. D, Dorsal; $\mathrm{L}$, lateral. The color wheel for the merged images is shown in $\boldsymbol{G}$. Scale bars: $\boldsymbol{H}, 200 \mu \mathrm{m} ; \boldsymbol{J}, 500 \mu \mathrm{m}$. The white lines shown in I and $\boldsymbol{J}$ demarcate the NST. 4V, Fourth ventricle; 7 , facial nucleus; DC, dorsal cochlear nucleus; icp, inferior cerebellar peduncle; MVePC, medial vestibular nucleus, parvicellular; sol, solitary tract; Sp50, spinal trigeminal nucleus, oral; SpVe, spinal vestibular nucleus.

\section{Discussion}

Deleting $B d n f$ in the tongue or in all tissues at adulthood resulted in an expansion of the terminal fields of gustatory nerves as they made their central contacts in the NST. We show here that deleting $B d n f$ in all tissues had more widespread effects on terminal field organization than if deleted only in the tongue. Thus, the maintenance of gustatory terminal field organization at adulthood requires normal expression of $B d n f$ in the peripheral targets of taste nerves and taste buds and is exaggerated when $B d n f$ is removed from other tissues. These effects are not attributable to changes in numbers of neurons or to changes in whole-nerve taste responses from the CT.

Deleting $B d n f$ at adulthood has opposite effects on maintenance of axonal branching of peripheral processes compared with central processes

The expansion of terminal fields is especially surprising because similar experimental treatments as those used here produced decreased branching of the CT in the tongue (Meng et al., 2015). Thus, the peripheral process of the CT decreases in branching whereas the central process of the same nerve expands when $B d n f$ is deleted at adulthood. Meng et al. (2015) showed that inducibly deleting $B d n f$ in the tongue or in all tissues in adult mice with the same genetic strategy used here resulted in an $\sim 40 \%$ loss of innervations and a 30\% decrease in taste bud cell size and in taste cell numbers, without a loss of neurons or taste buds. These effects were attributed, in part, to deficiencies in nerve/target (i.e., CT/taste bud) matching (Meng et al., 2015). Briefly, taste bud cells produce BDNF during development to recruit incoming axons (Nosrat et al., 1996, 2001; Hoshino et al., 2010; Huang and Krimm, 2010). BDNF production continues into adulthood (Yee et al., 2003), which likely maintains normal taste bud morphology and numbers (Farbman, 1969; Cheal and Oakley, 1977; Whitehead et al., 1987; Guagliardo and Hill, 2007) during the lifelong renewal of taste bud cells (Beidler and Smallman, 1965). Therefore, deleting $B d n f$ in the tongue at adulthood leads to the loss of a critical factor that maintains normal, mutual interactions between taste buds and their innervating neurons.

The central effects of $B d n f$ deletion are unusual in their effects

Our finding here that terminal fields are expanded in the NST in mice where $B d n f$ is deleted at adulthood suggests different mechanisms operate at both ends of the 
Table 2. Mean ( \pm SEM) taste responses (response/0.5 $\mathrm{M} \mathrm{NH}_{4} \mathrm{Cl}$ response)

\begin{tabular}{|c|c|c|c|c|c|c|c|c|c|}
\hline \multirow[b]{2}{*}{ Concentration (M) } & \multicolumn{3}{|c|}{ Controls } & \multicolumn{3}{|c|}{$\begin{array}{l}\text { K14-Bdnf } \\
\text { iKO No TAM }\end{array}$} & \multicolumn{3}{|c|}{ K14-BdnfiK0 } \\
\hline & Mean & $\pm S E M$ & $n$ & Mean & \pm SEM & $n$ & Mean & \pm SEM & $n$ \\
\hline \multicolumn{10}{|l|}{$\mathrm{NaCl}$} \\
\hline 0.05 & 0.181 & 0.04 & 8 & 0.117 & 0.02 & 6 & 0.108 & 0.01 & 5 \\
\hline 0.10 & 0.331 & 0.05 & 8 & 0.287 & 0.02 & 6 & 0.284 & 0.03 & 5 \\
\hline 0.25 & 0.664 & 0.07 & 8 & 0.580 & 0.04 & 6 & 0.612 & 0.06 & 5 \\
\hline 0.50 & 0.915 & 0.06 & 8 & 0.859 & 0.06 & 6 & 0.864 & 0.05 & 5 \\
\hline \multicolumn{10}{|l|}{$\mathrm{NaCl}$ with amiloride } \\
\hline 0.05 & 0.000 & 0.00 & 6 & 0.030 & 0.02 & 6 & 0.004 & 0.00 & 5 \\
\hline 0.10 & 0.010 & 0.01 & 6 & 0.042 & 0.02 & 6 & 0.026 & 0.01 & 5 \\
\hline 0.25 & 0.108 & 0.02 & 6 & 0.124 & 0.03 & 6 & 0.154 & 0.02 & 5 \\
\hline \multirow[t]{2}{*}{0.50} & 0.336 & 0.02 & 6 & 0.290 & 0.01 & 6 & 0.340 & 0.03 & 5 \\
\hline & \multicolumn{3}{|c|}{ Controls } & \multicolumn{3}{|c|}{$\begin{array}{l}\text { UBC-Bdnf } \\
\text { iKO No TAM }\end{array}$} & \multicolumn{3}{|c|}{ UBC-Bdnf iKO } \\
\hline Concentration (м) & Mean & \pm SEM & $n$ & Mean & \pm SEM & $n$ & Mean & \pm SEM & $n$ \\
\hline \multicolumn{10}{|l|}{$\mathrm{NaCl}$} \\
\hline 0.05 & 0.104 & 0.02 & 8 & 0.138 & 0.02 & 6 & 0.115 & 0.02 & 7 \\
\hline 0.10 & 0.245 & 0.02 & 8 & 0.314 & 0.02 & 6 & 0.253 & 0.03 & 7 \\
\hline 0.25 & 0.556 & 0.04 & 8 & 0.545 & 0.05 & 6 & 0.571 & 0.03 & 7 \\
\hline 0.50 & 0.735 & 0.05 & 8 & 0.763 & 0.03 & 6 & 0.770 & 0.05 & 7 \\
\hline \multicolumn{10}{|l|}{$\mathrm{NaCl}$ with amiloride } \\
\hline 0.05 & 0.013 & 0.01 & 7 & 0.000 & 0.00 & 5 & 0.006 & 0.00 & 7 \\
\hline 0.10 & 0.032 & 0.02 & 7 & 0.016 & 0.01 & 5 & 0.049 & 0.02 & 7 \\
\hline 0.25 & 0.167 & 0.03 & 7 & 0.150 & 0.01 & 5 & 0.227 & 0.03 & 7 \\
\hline \multirow[t]{2}{*}{0.50} & 0.324 & 0.02 & 7 & 0.258 & 0.02 & 5 & 0.360 & 0.03 & 7 \\
\hline & \multicolumn{3}{|c|}{ Controls } & \multicolumn{3}{|c|}{$\begin{array}{l}\text { K14-Bdnf } \\
\text { iKO No TAM }\end{array}$} & \multicolumn{3}{|c|}{ K14-Bdnf iK0 } \\
\hline Concentration (mм) & Mean & \pm SEM & $n$ & Mean & \pm SEM & $n$ & Mean & \pm SEM & $n$ \\
\hline \multicolumn{10}{|l|}{ Citric acid } \\
\hline 10 & 0.126 & 0.04 & 9 & 0.185 & 0.07 & 6 & 0.191 & 0.04 & 9 \\
\hline 20 & 0.320 & 0.04 & 9 & 0.356 & 0.06 & 6 & 0.476 & 0.04 & 9 \\
\hline \multirow[t]{2}{*}{50} & 0.588 & 0.04 & 9 & 0.511 & 0.07 & 6 & 0.642 & 0.06 & 9 \\
\hline & \multicolumn{3}{|c|}{ Controls } & \multicolumn{3}{|c|}{$\begin{array}{l}\text { UBC-Bdnf } \\
\text { iKO No TAM }\end{array}$} & \multicolumn{3}{|c|}{ UBC-Bdnf iKO } \\
\hline Concentration (mM) & Mean & \pm SEM & $n$ & Mean & \pm SEM & $n$ & Mean & \pm SEM & \\
\hline
\end{tabular}

\begin{tabular}{|c|c|c|c|c|c|c|c|c|c|}
\hline \multicolumn{10}{|l|}{ Citric acid } \\
\hline 10 & 0.143 & 0.05 & 7 & 0.154 & 0.05 & 6 & 0.165 & 0.02 & 9 \\
\hline 20 & 0.356 & 0.04 & 7 & 0.330 & 0.06 & 6 & 0.376 & 0.04 & 9 \\
\hline 50 & 0.620 & 0.05 & 7 & 0.583 & 0.06 & 6 & 0.627 & 0.06 & 9 \\
\hline \multirow[b]{2}{*}{ Concentration (M) } & \multicolumn{6}{|c|}{$\begin{array}{l}\text { K14-Bdnf } \\
\text { iKO No TAM }\end{array}$} & \multicolumn{3}{|c|}{ K14-Bdnf iK0 } \\
\hline & Mean & \pm SEM & $n$ & Mean & \pm SEM & $n$ & Mean & \pm SEM & $n$ \\
\hline \multicolumn{10}{|l|}{ Sucrose } \\
\hline 0.10 & 0.237 & 0.06 & 9 & 0.241 & 0.09 & 6 & 0.323 & 0.07 & 7 \\
\hline 0.25 & 0.462 & 0.08 & 9 & 0.508 & 0.12 & 6 & 0.536 & 0.08 & 7 \\
\hline 0.50 & 0.529 & 0.07 & 9 & 0.604 & 0.09 & 6 & 0.571 & 0.08 & 7 \\
\hline \multirow[t]{2}{*}{1.00} & 0.544 & 0.06 & 9 & 0.605 & 0.08 & 6 & 0.566 & 0.07 & 7 \\
\hline & \multicolumn{3}{|l|}{ Controls } & \multicolumn{3}{|c|}{$\begin{array}{l}\text { UBC-Bdnf } \\
\text { iKO No TAM }\end{array}$} & \multicolumn{3}{|c|}{ UBC-Bdnf iKO } \\
\hline Concentration (M) & Mean & $\pm S E M$ & $n$ & Mean & \pm SEM & $n$ & Mean & \pm SEM & $n$ \\
\hline \multicolumn{10}{|l|}{ Sucrose } \\
\hline 0.10 & 0.237 & 0.06 & 9 & 0.196 & 0.04 & 5 & 0.253 & 0.04 & 6 \\
\hline 0.25 & 0.462 & 0.08 & 9 & 0.382 & 0.04 & 5 & 0.492 & 0.09 & 6 \\
\hline 0.50 & 0.529 & 0.07 & 9 & 0.519 & 0.08 & 5 & 0.548 & 0.08 & 6 \\
\hline \multirow[t]{2}{*}{1.00} & 0.544 & 0.06 & 9 & 0.565 & 0.09 & 5 & 0.524 & 0.06 & 6 \\
\hline & \multicolumn{3}{|c|}{ Controls } & \multicolumn{3}{|c|}{$\begin{array}{l}\text { K14-Bdnf } \\
\text { iKO No TAM }\end{array}$} & \multicolumn{3}{|c|}{ K14-BdnfiKO } \\
\hline Concentration (mM) & Mean & \pm SEM & $n$ & Mean & \pm SEM & $n$ & Mean & \pm SEM & $n$ \\
\hline \multicolumn{10}{|l|}{ Quinine $\mathrm{HCl}$} \\
\hline 10 & 0.060 & 0.02 & 9 & 0.084 & 0.02 & 6 & 0.104 & 0.02 & 6 \\
\hline 20 & 0.121 & 0.05 & 9 & 0.147 & 0.02 & 6 & 0.154 & 0.04 & 6 \\
\hline
\end{tabular}

Table 2. Continued

\begin{tabular}{|c|c|c|c|c|c|c|c|c|c|}
\hline \multirow[b]{2}{*}{ Concentration (mм) } & \multicolumn{3}{|c|}{ Controls } & \multicolumn{3}{|c|}{$\begin{array}{l}\text { K14-Bdnf } \\
\text { iKO No TAM }\end{array}$} & \multicolumn{3}{|c|}{ K14-BdnfiK0 } \\
\hline & Mean & \pm SEM & $n$ & Mean & \pm SEM & $n$ & Mean & \pm SEM & $n$ \\
\hline 50 & 0.265 & 0.04 & 9 & 0.275 & 0.06 & 6 & 0.315 & 0.05 & 6 \\
\hline \multirow[t]{2}{*}{100} & 0.282 & 0.03 & 9 & 0.381 & 0.06 & 6 & 0.328 & 0.04 & 6 \\
\hline & \multicolumn{3}{|c|}{ Controls } & \multicolumn{3}{|c|}{$\begin{array}{l}\text { UBC-Bdnf } \\
\text { iKO No TAM }\end{array}$} & \multicolumn{3}{|c|}{ UBC-BdnfiKO } \\
\hline Concentration (mM) & Mean & \pm SEM & $n$ & Mean & \pm SEM & $n$ & Mean & \pm SEM & $n$ \\
\hline \multicolumn{10}{|l|}{ Quinine $\mathrm{HCl}$} \\
\hline 10 & 0.060 & 0.02 & 9 & 0.030 & 0.03 & 7 & 0.063 & 0.05 & 6 \\
\hline 20 & 0.121 & 0.05 & 9 & 0.089 & 0.03 & 7 & 0.097 & 0.04 & 6 \\
\hline 50 & 0.265 & 0.04 & 9 & 0.294 & 0.04 & 7 & 0.265 & 0.06 & 6 \\
\hline 100 & 0.282 & 0.03 & 9 & 0.311 & 0.04 & 7 & 0.310 & 0.05 & 6 \\
\hline
\end{tabular}

The table shows the mean, SEM, and number of animals per group $(n)$ for relative taste responses from the $C T$ to a concentration series of $\mathrm{NaCl}$ before and after lingual application to amiloride and to a concentration series of citric acid, sucrose, and quinine hydrochloride in controls, K14-Bdnf IKO No TAM, and K14-Bdnf iKO mice and for the CT in controls, UBC-Bdnf iKO No TAM, and UBC-Bdnf iKO mice.

same nerve. Moreover, this increase in size of the central projections does not match what may be expected from many other studies that examine the role of BDNF on axonal arbors and dendritic structures.

In addition to a key feature of neurotrophins to support neuronal survival during early development (Levi-Montalcini and Hamburger, 1951; Levi-Montalcini and Cohen, 1956; LeviMontalcini and Angeletti, 1963), they also impact the architecture of axonal arbors and dendritic structure during development as well as maintaining presynaptic and postsynaptic structures. Such roles have been identified for BDNF. An excess of this neurotrophin produces more complex and longer axonal arbors in projecting neurons during development (Davies et al., 1986; Cohen-Cory and Fraser, 1995; Huang and Reichardt, 2001; Poo, 2001; Cohen-Cory et al., 2010) and at adulthood (Thanos et al., 1989) and increases in the number of synapses on dendrites, dendritic lengths, and branching (Cohen-Cory and Fraser, 1995; Alsina et al., 2001; Cohen-Cory et al., 2010). Conversely, loss of BDNF and/or its receptor, TrkB, often results in a paring back of the terminal fields (Cohen-Cory, 1999). Given these findings, we would predict smaller instead of expanded terminal fields when $B d n f$ was deleted. However, there is an important finding from studies in the Xenopus visual system that may inform our results. In the Xenopus retinotectal pathway, BDNF has opposite effects on the branching of terminal fields in the tectum than it does on retinal ganglion cell dendrites (Lom and Cohen-Cory, 1999; Lom et al., 2002). Thus, the differential spatial effects on branching of the same neuron are similar to what we and Meng et al. (2015) show in the peripheral gustatory system and point to the importance of spatially dependent processes (i.e., peripheral vs central) in determining how axonal processes respond to alterations in $B d n f$ expression.

\section{Lack of "competition" among gustatory terminal fields in the} NST produces an immature organization

We are struck by the similarity of terminal field organization in our experimental mice here with that described in multiple experimental studies of the terminal field organization in rodents. In particular, it appears that a diverse set of experimental manipulations leads to a "reversion" to the immature terminal field organization found in early postnatal rats and mice (May and Hill, 2006; Zheng et al., 2014). Briefly, during early development, the CT, GSP, and IX all send extensive and mostly overlapping projections to the NST. This organization is then significantly refined in control animals from approximately P15 to P30, at 
A

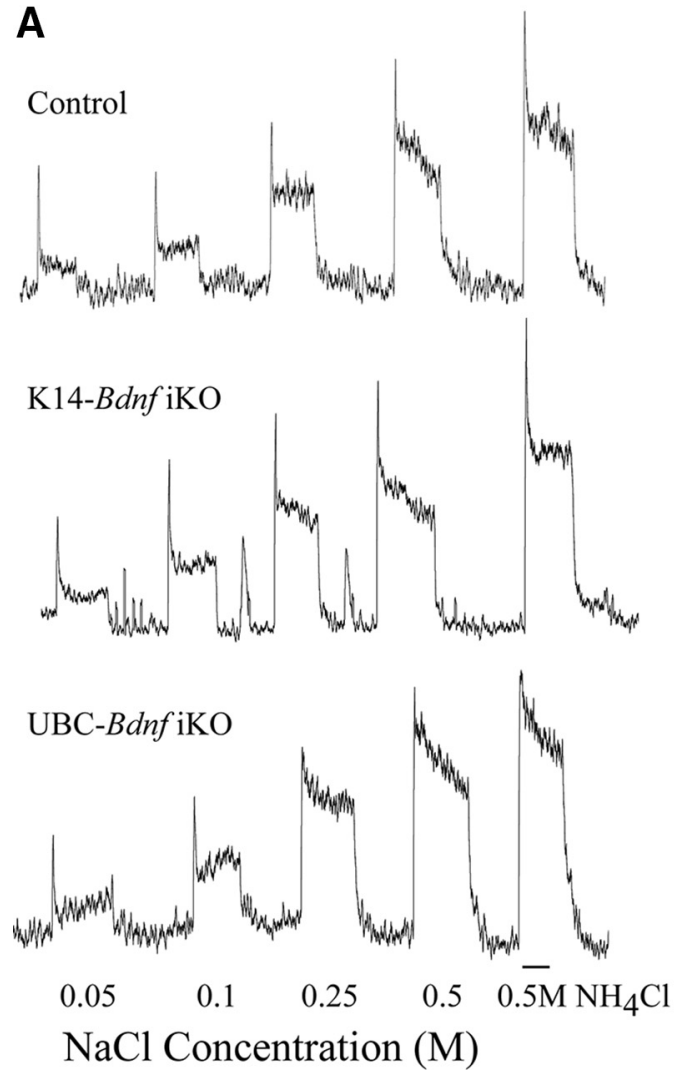

B

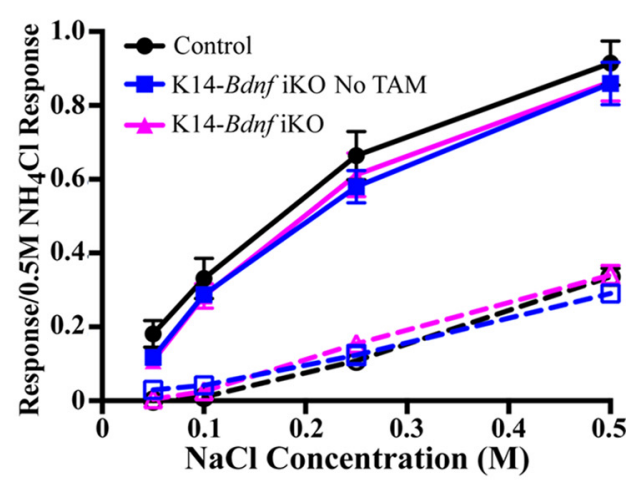

C

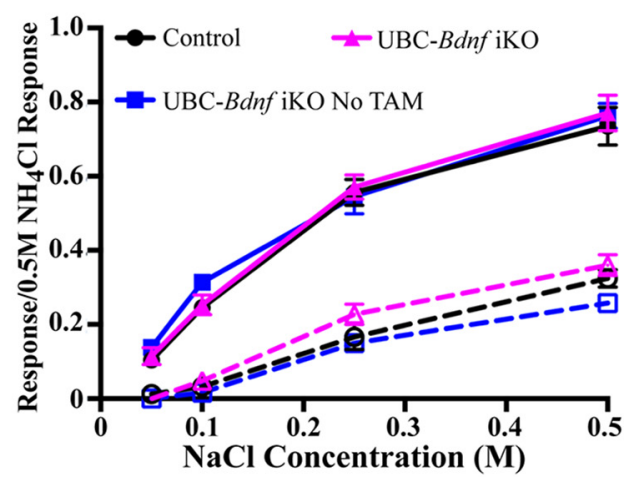

Figure 5. $\quad A$, Integrated taste responses from the $\mathrm{CT}$ in a control (top), a K14-Bdnf iKO (middle), and a UBC- $B d n f$ iKO (bottom) mouse to a concentration series of $\mathrm{NaCl}$ and to $0.5 \mathrm{M} \mathrm{NH} \mathrm{Cl}_{4}$. The scale bar shown near response to $0.5 \mathrm{M} \mathrm{NH}_{4} \mathrm{Cl}$ in a UBC-Bdnf iKO mouse is $20 \mathrm{~s}$. $\boldsymbol{B}$, Mean ( $\pm \mathrm{SEM}$ ) relative taste responses to a concentration series of NaCl from the CT in control, $\mathrm{K} 14-B d n f$ iKO No TAM, and $\mathrm{K} 14-B d n f$ iKO mice before (solid lines) and with lingual application of amiloride (dashed lines). C, Mean ( \pm SEM) relative taste responses to a concentration series of NaCl from the CT in control, UBC-Bdnf iKO No TAM, and UBC-Bdnf iKO mice before (dashed lines) and with lingual application of amiloride (dotted lines).

which age each of the terminal fields occupy distinct and more focused regions in the NST (Mangold and Hill, 2008). The immature terminal field organization is shared with adult rodents that have a history of early or lifelong dietary $\mathrm{NaCl}$ manipulations (May and Hill, 2006; Mangold and Hill, 2008; Zheng et al., 2014), deletion of the primary sodium taste transduction pathway during development (Sun et al., 2017) or at adulthood (Skyberg et al., 2017), and overexpression of $B d n f$ at inappropriate locations in the tongue throughout development (Sun et al., 2015) and in the CT of rodents that have the GSP and IX cut at adulthood (Corson and Hill, 2011). Our conclusion from these diverse studies is that alterations in the normal competition among the three terminal fields (e.g., changes in taste-elicited activity, amount of innervation) during development or at adulthood lead to a reestablishment of the immature terminal field seen in young control rodents. That is, a lack of competition for factors, which may include neurotrophins, modulatory molecules, and synaptic sites, leads to the expanded terminal field organization (Thoenen, 1995; Singh and Miller, 2005; Singh et al., 2008). One hypothesis, which may more directly relate to the findings here, may be that a decrease in the amount of anterogradely transported release of BDNF from the terminals (Zhou and Rush, 1996; Conner et al., 1997; Altar and DiStefano, 1998; Fawcett et al., 1998; Tonra et al., 1998; Tonra, 1999) of one or more gustatory nerves could destabilize taste nerve synapses onto their target NST cells. Findings from rat show that central taste neurons in the NST become less narrowly tuned but increase in response frequencies (i.e., amplify the taste signal) with age (Hill et al., 1983), suggesting that more synapses from more peripheral neurons are recruited during de- velopment. Lack of an organizing signal, such as BDNF, may lead to a disassembly of these circuits that resemble the immature organization. Indeed, evidence from other systems demonstrates that BDNF stabilizes synapses (Hu et al., 2005; Je et al., 2012).

We also suggest that expanded terminal fields in both K14$B d n f \mathrm{iKO}$ and UBC-Bdnf $\mathrm{iKO}$ mice are attributable primarily to the reduced amount of anterogradely transported, taste budderived BDNF. The additive $B d n f$ deletion in ganglia and NST may explain the exaggerated effects seen in UBC- $B d n f \mathrm{iKO}$ mice. Obviously, this hypothesis is speculative and requires more careful, mechanistic investigations that will enable an explanation of the significant amount of plasticity of these terminal fields during development and at adulthood.

\section{Implications for central taste function and taste-related behaviors}

Our findings that functional CT taste responses are not affected in mice with $B d n f$ deletion is surprising, given there are significant group-related differences in axonal branching and the numbers of taste bud cells (Meng et al., 2015). However, a recent report in which taste buds were removed pharmacologically showed that CT-relative taste responses were intact even with an $\sim 50 \%$ decrease in the number of taste buds (Kumari et al., 2017). This not only supports our functional data but also illustrates how resilient the peripheral gustatory system is in sending stimulus-specific information to the brain. Nonetheless, because we can only analyze relative response magnitudes from whole nerves (Beidler, 1953), there may be an overall decrease in afferent activity in our experimental animals that could influence 
activity-dependent processes impacting synapse formation and stabilization. Regardless of the mechanism(s), our findings of the enlarged terminal fields strongly indicate that functional changes in the central gustatory circuitry likely occur. For example, if more functional synapses accompany the increase terminal field volumes, there may be a broadening of gustatory information received by single NST neurons. This would potentially lead to significant changes in coding of taste quality and concentration at the first central relay. In turn, the deletion of $B d n f$ at adulthood could also lead to significant behavioral consequences, including alterations in taste thresholds, taste discrimination, and tasterelated ingestive behaviors.

In short, we show that the maintenance of the adult mouse central gustatory system is especially plastic and dependent on $B d n f$ expression in the tongue and in other tissues. As such, it is an ideal system to study circuit plasticity at adulthood and the role of neurotrophins in controlling neuronal structure and function.

\section{References}

Alsina B, Vu T, Cohen-Cory S (2001) Visualizing synapse formation in arborizing optic axons in vivo: dynamics and modulation by BDNF. Nat Neurosci 4:1093-1101. CrossRef Medline

Altar CA, DiStefano PS (1998) Neurotrophin trafficking by anterograde transport Trends Neurosci 21:433-437. Medline

Bartel DL, Finger TE (2013) Reactive microglia after taste nerve injury: comparison to nerve injury models of chronic pain. F1000Res 2:65. Medline

Beidler LM (1953) Properties of chemoreceptors of tongue of rat. J Neurophysiol 16:595-607. CrossRef Medline

Beidler LM, Smallman RL (1965) Renewal of cells within taste buds. J Cell Biol 27:263-272. CrossRef Medline

Benos DJ (1982) Amiloride: a molecular probe of sodium transport in tissues and cells. Am J Physiol 242:C131-C145. CrossRef Medline

Brady R, Zaidi SI, Mayer C, Katz DM (1999) BDNF is a target-derived survival factor for arterial baroreceptor and chemoafferent primary sensory neurons. J Neurosci 19:2131-2142. CrossRef Medline

Cheal M, Oakley B (1977) Regeneration of fungiform taste buds: temporal and spatial characteristics. J Comp Neurol 172:609-626. CrossRef Medline

Cohen-Cory S (1999) BDNF modulates, but does not mediate, activitydependent branching and remodeling of optic axon arbors in vivo. J Neurosci 19:9996-10003. CrossRef Medline

Cohen-Cory S, Fraser SE (1995) Effects of brain-derived neurotrophic factor on optic axon branching and remodelling in vivo. Nature 378:192196. CrossRef Medline

Cohen-Cory S, Kidane AH, Shirkey NJ, Marshak S (2010) Brain-derived neurotrophic factor and the development of structural neuronal connectivity. Dev Neurobiol 70:271-288. Medline

Conner JM, Lauterborn JC, Yan Q, Gall CM, Varon S (1997) Distribution of brain-derived neurotrophic factor (BDNF) protein and mRNA in the normal adult rat CNS: evidence for anterograde axonal transport. J Neurosci 17:2295-2313. CrossRef Medline

Corson SL, Hill DL (2011) Chorda tympani nerve terminal field maturation and maintenance is severely altered following changes to gustatory nerve input to the nucleus of the solitary tract. J Neurosci 31:7591-7603. CrossRef Medline

Davies AM, Thoenen H, Barde YA (1986) The response of chick sensory neurons to brain-derived neurotrophic factor. J Neurosci 6:1897-1904. CrossRef Medline

Davis BJ (1988) Computer-generated rotation analyses reveal a key threedimensional feature of the nucleus of the solitary tract. Brain Res Bull 20:545-548. CrossRef Medline

Farbman AI (1969) Fine structure of degenerating taste buds after denervation. J Embryol Exp Morphol 22:55-68. Medline

Fawcett JP, Bamji SX, Causing CG, Aloyz R, Ase AR, Reader TA, McLean JH, Miller FD (1998) Functional evidence that BDNF is an anterograde neuronal trophic factor in the CNS. J Neurosci 18:2808-2821. CrossRef Medline

Frank ME (1991) Taste-responsive neurons of the glossopharyngeal nerve of the rat. J Neurophysiol 65:1452-1463. CrossRef Medline
Ganchrow D, Ganchrow JR, Cicchini V, Bartel DL, Kaufman D, Girard D, Whitehead MC (2014) Nucleus of the solitary tract in the C57BL/6] mouse: subnuclear parcellation, chorda tympani nerve projections, and brainstem connections. J Comp Neurol 522:1565-1596. CrossRef Medline

Guagliardo NA, Hill DL (2007) Fungiform taste bud degeneration in C57BL/6 J mice following chorda-lingual nerve transection. J Comp Neurol 504:206-216. CrossRef Medline

Hellekant G, af Segerstad CH, Roberts T, van der Wel H, Brouwer JN, Glaser D, Haynes R, Eichberg JW (1985) Effects of gymnemic acid on the chorda tympani proper nerve responses to sweet, sour, salty and bitter taste stimuli in the chimpanzee. Acta Physiol Scand 124:399-408. CrossRef Medline

Hill DL, Bradley RM, Mistretta CM (1983) Development of taste responses in rat nucleus of solitary tract. J Neurophysiol 50:879-895. CrossRef Medline

Hoshino N, Vatterott P, Egwiekhor A, Rochlin MW (2010) Brain-derived neurotrophic factor attracts geniculate ganglion neurites during embryonic targeting. Dev Neurosci 32:184-196. CrossRef Medline

Hu B, Nikolakopoulou AM, Cohen-Cory S (2005) BDNF stabilizes synapses and maintains the structural complexity of optic axons in vivo. Development 132:4285-4298. CrossRef Medline

Huang EJ, Reichardt LF (2001) Neurotrophins: roles in neuronal development and function. Annu Rev Neurosci 24:677-736. CrossRef Medline

Huang T, Krimm RF (2010) Developmental expression of bdnf, Ntf4/5, and TrkB in the mouse peripheral taste system. Dev Dyn 239:2637-2646. CrossRef Medline

Je HS, Yang F, Ji Y, Nagappan G, Hempstead BL, Lu B (2012) Role of probrain-derived neurotrophic factor (proBDNF) to mature BDNF conversion in activity-dependent competition at developing neuromuscular synapses. Proc Natl Acad Sci U S A 109:15924-15929. CrossRef Medline

Kumari A, Ermilov AN, Grachtchouk M, Dlugosz AA, Allen BL, Bradley RM, Mistretta CM (2017) Recovery of taste organs and sensory function after severe loss from Hedgehog/Smoothened inhibition with cancer drug sonidegib. Proc Natl Acad Sci U S A 114:E10369-E10378. CrossRef Medline

Lasiter PS, Wong DM, Kachele DL (1989) Postnatal development of the rostral solitary nucleus in rat: dendritic morphology and mitochondrial enzyme activity. Brain Res Bull 22:313-321. CrossRef Medline

Levi-Montalcini R, Angeletti PU (1963) Essential role of the nerve growth factor in the survival and maintenance of dissociated sensory and sympathetic embryonic nerve cells in vitro. Dev Biol 7:653-659. CrossRef

Levi-Montalcini R, Cohen S (1956) In vitro and in vivo effects of a nerve growth-stimulating agent isolated from snake venom. Proc Natl Acad Sci U S A 42:695-699. CrossRef Medline

Levi-Montalcini R, Hamburger V (1951) Selective growth stimulating effects of mouse sarcoma on the sensory and sympathetic nervous system of the chick embryo. J Exp Zool 116:321-361. CrossRef Medline

Lom B, Cohen-Cory S (1999) Brain-derived neurotrophic factor differentially regulates retinal ganglion cell dendritic and axonal arborization in vivo. J Neurosci 19:9928-9938. CrossRef Medline

Lom B, Cogen J, Sanchez AL, Vu T, Cohen-Cory S (2002) Local and targetderived brain-derived neurotrophic factor exert opposing effects on the dendritic arborization of retinal ganglion cells in vivo. J Neurosci 22: 7639-7649. CrossRef Medline

Ma L, Lopez GF, Krimm RF (2009) Epithelial-derived brain-derived neurotrophic factor is required for gustatory neuron targeting during a critical developmental period. J Neurosci 29:3354-3364. CrossRef Medline

Mangold JE, Hill DL (2008) Postnatal reorganization of primary afferent terminal fields in the rat gustatory brainstem is determined by prenatal dietary history. J Comp Neurol 509:594-607. CrossRef Medline

May OL, Hill DL (2006) Gustatory terminal field organization and developmental plasticity in the nucleus of the solitary tract revealed through triple-fluorescence labeling. J Comp Neurol 497:658-669. CrossRef Medline

Mbiene JP, Mistretta CM (1997) Initial innervation of embryonic rat tongue and developing taste papillae: nerves follow distinctive and spatially restricted pathways. Acta Anat (Basel) 160:139-158. CrossRef

Meng L, Ohman-Gault L, Ma L, Krimm RF (2015) Taste bud-derived BDNF is required to maintain normal amounts of innervation to adult taste buds. eNeuro 2:pii:ENEURO.0097-15.2015. CrossRef Medline

Nosrat CA, Ebendal T, Olson L (1996) Differential expression of brain- 
derived neurotrophic factor and neurotrophin 3 mRNA in lingual papillae and taste buds indicates roles in gustatory and somatosensory innervation. J Comp Neurol 376:587-602. CrossRef Medline

Nosrat CA, MacCallum DK, Mistretta CM (2001) Distinctive spatiotemporal expression patterns for neurotrophins develop in gustatory papillae and lingual tissues in embryonic tongue organ cultures. Cell Tissue Res 303:35-45. CrossRef Medline

Poo M (2001) Neurotrophins as synaptic modulators. Nat Rev Neurosci 2:24-32. Medline

Ridler TW, Calvard S (1978) Picture thresholding using an iterative selection method. IEEE Trans Syst Man Cyber 8:630-632. CrossRef

Ruzankina Y, Pinzon-Guzman C, Asare A, Ong T, Pontano L, Cotsarelis G, Zediak VP, Velez M, Bhandoola A, Brown EJ (2007) Deletion of the developmentally essential gene ATR in adult mice leads to age-related phenotypes and stem cell loss. Cell Stem Cell 1:113-126. CrossRef Medline

Shingai T, Beidler LM (1985) Response characteristics of three taste nerves in mice. Brain Res 335:245-249. CrossRef Medline

Singh KK, Miller FD (2005) Activity regulates positive and negative neurotrophin-derived signals to determine axon competition. Neuron 45:837-845. CrossRef Medline

Singh KK, Park KJ, Hong EJ, Kramer BM, Greenberg ME, Kaplan DR, Miller FD (2008) Developmental axon pruning mediated by BDNF-p75NTRdependent axon degeneration. Nat Neurosci 11:649-658. CrossRef Medline

Skyberg R, Sun C, Hill DL (2017) Maintenance of mouse gustatory terminal field organization is disrupted following selective removal of peripheral sodium salt taste activity at adulthood. J Neurosci 37:7619-7630. CrossRef Medline

Sun C, Dayal A, Hill DL (2015) Expanded terminal fields of gustatory nerves accompany embryonic BDNF overexpression in mouse oral epithelia. J Neurosci 35:409-421. CrossRef Medline
Sun C, Hummler E, Hill DL (2017) Selective deletion of sodium salt taste during development leads to expanded terminal fields of gustatory nerves in the adult mouse nucleus of the solitary tract. J Neurosci 37:660-672. CrossRef Medline

Thanos S, Bähr M, Barde YA, Vanselow J (1989) Survival and axonal elongation of adult rat retinal ganglion cells. Eur J Neurosci 1:19-26. CrossRef Medline

Thoenen H (1995) Neurotrophins and neuronal plasticity. Science 270: 593-598. CrossRef Medline

Tonra JR (1999) Classical and novel directions in neurotrophin transport and research: anterograde transport of brain-derived neurotrophic factor by sensory neurons. Microsc Res Tech 45:225-232. CrossRef Medline

Tonra JR, Curtis R, Wong V, Cliffer KD, Park JS, Timmes A, Nguyen T, Lindsay RM, Acheson A, DiStefano PS (1998) Axotomy upregulates the anterograde transport and expression of brain-derived neurotrophic factor by sensory neurons. J Neurosci 18:4374-4383. CrossRef Medline

Whitehead MC (1988) Neuronal architecture of the nucleus of the solitary tract in the hamster. J Comp Neurol 276:547-572. CrossRef Medline

Whitehead MC, Frank ME, Hettinger TP, Hou LT, Nah HD (1987) Persistence of taste buds in denervated fungiform papillae. Brain Res 405:192195. CrossRef Medline

Yee CL, Jones KR, Finger TE (2003) Brain-derived neurotrophic factor is present in adult mouse taste cells with synapses. J Comp Neurol 459:1524. CrossRef Medline

Zheng S, Sun C, Hill D (2014) Postnatal reorganization of primary gustatory afferent terminal fields in the mouse brainstem is altered by prenatal dietary sodium history. Soc Neurosci Abstr 40:780.16.

Zhou XF, Rush RA (1996) Endogenous brain-derived neurotrophic factor is anterogradely transported in primary sensory neurons. Neuroscience 74 : 945-953. CrossRef Medline 